NBER WORKING PAPER SERIES

\title{
RISKY BUSINESS? THE EFFECT OF MAJORING IN BUSINESS ON EARNINGS AND EDUCATIONAL ATTAINMENT
}

\author{
Rodney J. Andrews \\ Scott A. Imberman \\ Michael F. Lovenheim \\ Working Paper 23575 \\ http://www.nber.org/papers/w23575 \\ NATIONAL BUREAU OF ECONOMIC RESEARCH \\ 1050 Massachusetts Avenue \\ Cambridge, MA 02138 \\ July 2017
}

We gratefully acknowledge that this research was made possible through data provided by the University of Texas at Dallas Education Research Center. The conclusions of this research do not necessarily reflect the opinions or official position of the Texas Education Agency, the Texas Higher Education Coordinating Board, or the State of Texas. We would also like to thank Alyssa Carlson, Sara Muehlenbein, Katelyn Heath and Mark Lu for excellent research assistance. We are further grateful for generous financial support for this project provided by the Smith Richardson Foundation. Finally, we'd like to thank seminar participants at Association for Education Finance and Policy Annual Meeting, Association for Policy Analysis and Management International Meeting, Michigan State University, Teachers' College, University of Georgia, and University of Michigan for helpful comments and advice. The views expressed herein are those of the authors and do not necessarily reflect the views of the National Bureau of Economic Research.

NBER working papers are circulated for discussion and comment purposes. They have not been peer-reviewed or been subject to the review by the NBER Board of Directors that accompanies official NBER publications.

(C) 2017 by Rodney J. Andrews, Scott A. Imberman, and Michael F. Lovenheim. All rights reserved. Short sections of text, not to exceed two paragraphs, may be quoted without explicit permission provided that full credit, including $\odot$ notice, is given to the source. 
Risky Business? The Effect of Majoring in Business on Earnings and Educational Attainment Rodney J. Andrews, Scott A. Imberman, and Michael F. Lovenheim

NBER Working Paper No. 23575

July 2017

JEL No. I23,I26,J24

\begin{abstract}
$\underline{\text { ABSTRACT }}$
One of the most important decisions a student can make during the course of his or her college career is the choice of major. The field of study a student selects translates directly into the types of skills and knowledge he or she will obtain during college, and it can influence the type of career chosen after postsecondary education ends. Business is one of the most popular majors in the US, accounting for $19 \%$ of all college degrees granted. We study the impact of choosing a business major using a regression discontinuity design that exploits GPA cutoffs for switching majors in some Texas universities. Even though nearly $60 \%$ of marginal business majors would have majored in a STEM field otherwise, we find large and statistically significant increases in earnings of $80 \%$ to $130 \% 12+$ years after college entry, driven mainly by women. These are considerably larger than OLS estimates that condition on a rich set of demographic, high school achievement, and high school fixed-effects controls, which is consistent with students choosing majors based on comparative advantage. We do not find statistically significant effects of majoring in business on educational outcomes, except for positive effects on male 6-year graduation rates.
\end{abstract}

Rodney J. Andrews

The University of Texas at Dallas 800 West Campbell Road

MS WT21

Richardson, TX 75080

and NBER

rodney.j.andrews@utdallas.edu

Scott A. Imberman

Michigan State University

486 W. Circle Drive

110 Marshall-Adams Hall

East Lansing, MI 48824-1038

and NBER

imberman@msu.edu
Michael F. Lovenheim

Department of Policy Analysis and Management Cornell University

102 Martha Van Rensselaer Hall

Ithaca, NY 14853

and NBER

mfl55@cornell.edu 


\section{Introduction}

The returns to skill in the labor market are historically high. Extensive empirical evidence shows that investing in a college education leads to significant increases in future earnings (e.g., Hungerford and Solon, 1987; Ashenfelter and Krueger, 1994; Card, 1995; Kane and Rouse, 1995; Jaeger and Page, 1996; Keane and Wolpin, 1997; Zimmerman, 2014). However, examining average wage effects of a college education likely misses two important sources of heterogeneity that can produce a misleading picture of the returns to investing in postsecondary education. The first is heterogeneity in the returns to college quality, which has received much attention in the literature $1^{1}$ The second source of heterogeneity in the returns to college relates to the course of study a student selects. The returns to majoring in English may be very different from majoring in engineering or mathematics, for example. This heterogeneity can render the average college-level return a misleading indicator of student expectations over how their earnings will be impacted by a given postsecondary enrollment decision. To date, the return to college major choice has received far less attention by researchers than the other margins of postsecondary investment, especially in the United States. While it is widely believed that college major choice is an important determinant of the returns to postsecondary education, there is little evidence based on credible causal studies to support these beliefs.

The contention that major choice affects the returns to education is supported, in part, by the large difference in average earnings across majors. Carnevale and Cheah (2013) show that median earnings of recent graduates ranged from $\$ 54,000$ per year in engineering to around $\$ 30,000$ for recreation, arts or science degree holders. Kearney and Hershbein (2015) find that median lifetime earnings by major range from $\$ 800,000$ to $\$ 2$ million and that engineering, computer science, operations and logistics, physics, economics and finance pay the most. Major choices guide much of what a student will learn during college and have a large impact on

\footnotetext{
${ }^{1} \mathrm{~A}$ large body of prior work has found evidence of a positive causal effect of attending more selective or higher-resource schools on future earnings (Brewer, Eide and Ehrenberg, 1999; Black and Smith, 2004, 2006; Hoekstra, 2009; Andrews, Li and Lovenheim, 2016). This is especially the case for students from low-income backgrounds (Dale and Krueger, 2002, 2013; Andrews, Imberman and Lovenheim, 2016). Some of the return to college quality likely is driven by the fact that postsecondary quality/resources increase college completion rates (Bound, Lovenheim and Turner, 2010) and reduce the time it takes students to obtain a baccalaureate degree (Bound, Lovenheim and Turner, 2012).
} 
students' postsecondary experiences. One can argue that the choice of major field is the most important decision a student will make in college, perhaps even more important than the choice of which school to attend. Indeed, earnings difference across graduates of different majors is as large as or larger than the average earnings gap between high school and college graduates (Altonji, Blom and Meghir 2012). To the extent that rising demand for college workers has not been evenly spread across fields of study, it is essential to understand the return to college majors to inform optimal human capital decisions among students. In addition, understanding which majors have the highest returns is important for guiding resource allocation in the postsecondary sector: institutions may want to put more resources towards high return majors to best support the post-collegiate earnings of graduates.

It is difficult to estimate the causal effect of college major choice on earnings because students do not randomly select into majors. There is considerable evidence that the majors associated with the highest post-collegiate earnings are the majors that are selected by students with the highest measured pre-collegiate academic ability (Arcidiacono 2004). Several prior studies examine the relationship between college major choice and earnings, most of which attempt to account for selection by controlling for pre-collegiate ability measures (James et al. 1989; Grogger and Eide 1995; Hammermesh and Donald 2008; Kinsler and Pavan 2015) ${ }^{2}$ This approach is unlikely to uncover the causal impact of major choice because high school skill measures are an imperfect proxy for actual cognitive skill and because students in more technical and high-earnings majors almost certainly have higher non-cognitive skills that allow them to complete a more demanding course of study. Because these cognitive and non-cognitive skills are independently valued in the labor market (Heckman, Stixrud and Urzua 2006), estimates based on selection-on-observables methods are likely to be biased. $]^{3}$

This paper provides estimates of the return to college major choices that addresses several of

\footnotetext{
${ }^{2}$ See Altonji, Arcidiacono, and Maurel (2015) for a recent review of the literature.

${ }^{3}$ There also is a small body of work examining how major choice relates to postsecondary outcomes, which suggests major choices are correlated with persistence and completion (Leppel 2001; St. John et al. 2004). Using detailed administrative data from the state of Missouri, Arcidiacono and Koedel (2014) show that African American students who initially pursue STEM majors have lower graduation rates than similarly-prepared African American students who pursue non-STEM fields, possibly because STEM majors are more difficult (Koedel, 2011). While these studies are suggestive of a role for major choice in determining postsecondary outcomes, none uses an empirical strategy that is likely to overcome the selection biases driven by different types of students selecting different majors.
} 
the difficulties faced by prior research. Our focus is on the return to majoring in business, which is the single most popular field of study in the United States: In 2014, $19.2 \%$ of all bachelor degrees awarded in the United States were in business and management. In contrast, $11.5 \%$ of degrees were in liberal arts or humanities, $13.9 \%$ were in the social sciences, $5.3 \%$ were in education, $10.6 \%$ were in health professions, and $17.0 \%$ were in science, technology, engineering and math (STEM) fields 4 The popularity of the business major is not a new phenomenon. The demand for this major has been consistently high over the past several decades. Business majors tend to focus on providing students with skills and knowledge that currently are needed in the labor market, including finance, accounting, management and computer skills. There is much less emphasis on literature, philosophy, the arts, and the principles of scientific reasoning. The specific focus of this major has generated controversy among policymakers and educators. Proponents argue that this more focused training gives students skills that are highly valued by employers in the labor market, which leads to high earnings returns and provides employers the types of workers they need to foster economic growth. Opponents believe that training students more broadly - for example, in the liberal arts tradition - would allow them to be more productive workers in the long run and to be more adaptable to future changes in the demand for specific types of labor. Despite the persistently high demand for the business major and the significant resources states spend on supporting undergraduate business programs, both sides lack credible empirical support for their claims that is based on robust causal methods.

The main contribution of this paper is to fill some of the gaps in our knowledge about the effect of majoring in business on postsecondary and labor market outcomes, focusing on public universities in Texas. We employ rich administrative data from Texas that links students' K12 records to their higher education records if they attend a public postsecondary institution within the state. These data are then merged with administrative earnings information from

\footnotetext{
${ }^{4}$ These tabulations are taken from the 2016 Digest of Education Statistics produced by the US Department of Education. Some fields are agglomerated for exposition. In particular "liberal arts and humanities" includes, as defined in the Digest "liberal arts and sciences, general studies, and humanities," "philosophy and religious studies," "history," "foreign languages, literatures, and linguistics," "theology and religious vocations," and "visual and performing arts." "Social sciences" includes "social sciences" and "psychology." "STEM" includes "biological and biomedical sciences," "computer and information sciences," "engineering," "engineering technologies and engineering-related fields," "mathematics and statistics," and "physical sciences and science technologies."
} 
the unemployment insurance earnings system in Texas. Together, the data provide us with detailed information on students' pre-collegiate academic training, postsecondary outcomes, and earnings. Using these rich data, we estimate the causal effect of the decision to major in business on earnings and postsecondary outcomes using a regression discontinuity (RD) design. Specifically, we exploit the fact that students in some institutions who wish to switch into the business major from another major, an "undeclared" major or a "pre-business" major, must meet minimum college GPA requirements to do so. Students whose overall GPA has met a specified threshold have the option to declare a business major while some students who wish to switch cannot because they cannot exceed the threshold within a certain time since enrolling. Through this methodology, we are able to identify the causal impacts of majoring in business in five of the largest institutions in Texas: University of Texas at Austin, Texas A\&M University, Texas Tech University, University of Houston and University of Texas at Arlington.

We find that the likelihood that a student who begins college in a non-business major ends up as a business major increases by about 5\% at the GPA cutoff. This is a $71 \%$ increase relative to the likelihood of majoring in business just below the cutoffs. Almost $60 \%$ of these new business majors would have majored in a STEM field and another 9.4\% would have majored in Economics had they not had access to the business major. We use the option of majoring in business due to exceeding the GPA threshold to instrument for majoring in business. Specifically, we estimate two-stage least squares models that identify the effect of selecting a business major for the set of students who change major due to just qualifying for the option to do so relative to the distribution of counterfactual majors selected by students who just fail to qualify for the option to major in business.

Point estimates indicate that majoring in business increases 6- and 8-year graduation by 12-18 percentage points, although the estimates are not statistically significantly different from zero at conventional levels. Transferring drops by similar amounts, but those estimates also are not statistically significant. Our results point to large effects of majoring in business on earnings. Twelve or more years after initial college enrollment, earnings are 0.60 to $0.82 \log$ points (or $81 \%$ to $128 \%$ ) higher among those induced by the GPA cutoff rules to major in business, depending on the size of the bandwidth. This effect is almost twice as large as the 
effect $10+$ years after college enrollment, which suggests that returns to the business major grow with experience.

We compare these effects to OLS estimates that account for a rich set of student background controls as well as institution-cohort and high school fixed effects. These controls are more expansive than what has been used in the existing selection-on-observables literature:5 The OLS estimates suggest smaller returns of around 15\%, but the implicit counterfactual major distributions differ between the OLS and RD models, making it difficult to compare the two. A strength of our approach and data is that we can identify the distribution of alternative majors at the GPA cutoffs. We re-weight the OLS estimates by the relative size of the counterfactual major in the RD estimates, such that the OLS and RD estimates place similar weight on each non-business major. After making this adjustment, the OLS results show virtually no impact on earnings, in contrast to the $81 \%$ to $128 \%$ effect we estimate using RD. Results for postsecondary outcomes also are larger in the RD relative to the OLS estimates, although the imprecision of the results make us unable to statistically reject that the OLS and RD estimates are equal. That the RD model yields substantially larger earnings effects than the OLS model that incorporate rich controls is consistent with the findings of Kirkebøen, Leuven and Mogstad (2016) in Norway. They demonstrate that students who obtain access to their first-choice major have particularly large returns to that major, which is likely driven by student sorting on comparative advantage. This type of selection on unobserved skill or preferences likely drives our results as well. An important implication is that Texas institutions employing GPA cutoffs could increase the returns to college substantially for a subset of students by lowering the GPA requirements for business transfers.

The size of our analysis sample allows us to examine heterogeneity by gender and initial major choice. The earnings effects are concentrated among women, while the educational attainment effects are concentrated among men. For women, majoring in business increases earnings $12+$ years after college enrollment by 1.4 log points. Because most marginal business students would have majored in STEM, these findings suggest that the existence of the high-

\footnotetext{
${ }^{5}$ For example, see James et al. (1989), Altonji (1993), Rumberger and Thomas (1993), Loury and Garman (1995), Grogger and Eide (1995), Hammermesh and Donald (2008), Carnevale and Cheah (2013), and Hershbein and Kearney (2015).
} 
return business major can limit the effectiveness of policies designed to increase the rate of women entering STEM fields. We also show that the effects are particularly large among students whose first major is in a STEM field. These students experience a 1.6 log point increase in earnings from majoring in business. Interestingly, switching to business prolongs time to degree but also increases 6- and 8-year graduation rates by about $50 \%$.

Our paper makes three contributions to the literature. The first core contribution is to provide the only empirical analysis in the US of the return to an important college major using an identification strategy that can plausibly overcome biases associated with student selection. There are two prior studies that use a similar approach in Chile (Hastings, Neilson and Zimmerman 2013) and Norway (Kirkebøen, Leuven and Mogstad 2016). Both of these papers use the fact that students jointly apply to a postsecondary school and a program of study, and the admissions rules require programs to admit the best students according to a common metric. As a result, there are sharp admissions cutoffs for school-major combinations that support a regression discontinuity approach. They find evidence of large differences in the returns across college majors. For business in particular, Hastings, Neilson and Zimmerman estimate earnings returns of approximately 10\%, while Kirkebøen Leuven and Mogstad find positive returns to business relative to all alternative majors other than engineering.

Relative to these studies, our analysis makes several contributions. First, the US postsecondary system differs in critical ways from the Chilean and Norwegian contexts, making it very difficult to generalize the findings from these analyses to the United States. In particular, the timing of major choice differs substantially, as does the application process. In Chile and Norway, students apply to fields and institutions jointly upon entry to college, and opportunities to switch are extremely limited. In the US, on the other hand, the application system is decentralized, and while some institutions allow students to pick a field upon entry, switching is relatively easy and usually does not require another application process or a change of institutions. Typically, students are not required to (and often do not) pick a field upon first enrolling in college. Thus, there may be substantial differences in the types of students who are on the margins of major choice, and decisions about majors made in the second year of college may have different effects on later outcomes than decisions made in the last year of high 
school. While we examine only one state, Texas is quite large and diverse, and the structure and quality of its postsecondary system is much more representative of those of other states in the US than are the Chilean and Norwegian systems.

Second, all of the effects we identify are across students within a given school, while in these other studies they must assume that college quality and major effects are additively separable. Third, while Kirkebøen Leuven and Mogstad (2016) are able to identify relevant counterfactual field choices, Hastings, Neilson and Zimmerman (2013) are unable to construct such counterfactuals. The inability to measure counterfactual majors makes it difficult to interpret effects of major choice on labor market outcomes. Fourth, the Norwegian and Chilean economies differ substantially from the US in ways that make it very challenging to generalize results across countries. As a result, it is unclear whether the returns they estimate can generalize to the US.

The prior research on the return to majors in the US that most clearly addresses selection bias is Arcidiacono (2004). He derives and estimates a dynamic structural model of college choice and major choice. The model is flexible enough to allow students to experience majorspecific returns to ability and is identified predominantly off of period-specific shocks that allow students to react to information they are receiving about their own preferences and abilities as well as an "exclusion restriction" that state-average earnings only affect utility by impacting individual earnings and not preferences or abilities. Using data from the National Longitudinal Survey of 1972, he shows that the returns to college are highest for business and natural science majors.

While Arcidiacono (2004) provides a significant advancement over the previous selection-onobservables literature, his model ultimately is identified under the assumption that his structural model of college and major choices accurately reflects how students make these choices. That there is little understanding of why students select certain majors makes modeling this decision very difficult. Furthermore, most of the people he studies went to college in the 1970s and 1980s. Generalizing these results to current and future students is difficult, given the large increases in the return to skill that have occurred since that time. Hence, it is important to generate evidence on the returns to college major choice using more recent students. Our study is the only other paper using US data that attempts to estimate the causal effect of choosing 
a particular college major on earnings, and it is the only one that uses quasi-experimental variation to overcome the problems caused by selection of students with different abilities and preferences into different majors. Furthermore, the students we examine attended college in the 2000s, so their experiences are more likely to reflect the return to major choice faced by students currently in the postsecondary system.

The second main contribution of our paper is the comparison of OLS and RD estimates in a manner that accounts for the local nature of the RD parameter. Because we observe the distribution of counterfactual majors, we can reweight the OLS results such that the RD and OLS estimates employ the same distribution of alternative majors. This is novel in the return to college major literature and allows a more direct assessment of the role of selection in driving any differences between OLS and IV results.

Finally, we provide the first analysis in the literature on how major choice affects postsecondary outcomes in a manner that more plausibly handles selection bias than selection-onobservables models. None of the other papers that use an RD approach in other countries estimate impacts on potentially important educational outcomes such as graduation, graduate school attendance and transferring. These are important outcomes that can potentially impact lifetime outcomes through avenues not captured by earnings, and they can help explain some of the earnings effects. Indeed, Kirkebøen Leuven and Mogstad (2016) focus on college graduates under the assumption that the major field does not affect graduation likelihood. While they provide evidence of this in Norway, in the US and many other more decentralized broad access systems, dropouts are very common and field choice can plausibly impact completion. Arcidiacono (2004) also does not examine educational outcomes, which underscores the novelty of the evidence we provide on how major choice affects postsecondary outcomes.

\section{Data}

We use detailed administrative data linking K-12 education, postsecondary, and earnings records for all students and workers in the State of Texas who attend a public secondary school and a public college or university. The K-12 portion of the data contains a host of background 
characteristics that are useful in assessing the extent of selection into the business major. For all students who went to high school in Texas, we observe the high school in which he or she was enrolled, scores from state standardized tests, and a large set of demographic and educational characteristics such as race/ethnicity, gender, whether the student was eligible for free or reduced-price lunch, whether the student was at risk of dropping out, and enrollment in gifted and talented programs. The test score data we use are from the $11^{\text {th }}$ grade Texas Assessment of Academic Skills (TAAS) exams for reading, writing and mathematics from 1997 to 2002 and for the Texas Assessment of Knowledge and Skills (TAKS) for students in $11^{\text {th }}$ grade in 2003 and later. The TAAS and TAKS exams are administered to all students in Texas, and they are "high stakes" in the sense that students must achieve a passing score on them in order to graduate. Because students can retake them, we use the lowest score for each student, which typically corresponds to the score from the first time students take the exam.

Data on students' college careers come from the Texas Higher Education Coordinating Board (THECB). We observe, on a semester-by-semester basis, the institution in which the student is enrolled, declared major field of study, enrollment in public Texas graduate degree programs, credits attempted and grade points earned. The data also include the timing of degree receipt for each degree earned from a public Texas institution. To calculate cumulative GPA, we divide the cumulative grade points earned by the cumulative credits attempted in each semester. College credit data are only available for all postsecondary institutions beginning in 1999, so we restrict our analysis samples to those who began college in 1999 and after. The THECB only collects this information for people attending a public college or university in Texas, but given the high quality and low cost of the Texas public postsecondary system, the vast majority of students attend in-state (Andrews, Imberman and Lovenheim 2016). While we have postsecondary data for all students in the Texas public system, our analysis sample uses only those students who also graduated from high school in Texas so that we can link postsecondary records to K-12 records. This constitutes $61 \%$ of students in the THECB data.6

While we observe college majors for each semester, we focus on major selection at two

\footnotetext{
${ }^{6}$ This restriction is done so that we can test for selection across the GPA discontinuity as a function of pre-determined characteristics and so that we can control for such characteristics in our regression analysis.
} 
distinct points in time. The first is in the initial semester of enrollment; GPA cutoffs for access to business majors apply only to students who do not initially declare business as a major. Thus, our main analysis sample contains those who do not declare a business major as of their first semester of enrollment. The second time at which we measure major choice is at the end of undergraduate enrollment. We define "final major" as the major at graduation or the final major in which we observe an undergraduate student before her enrollment ends without a degree. We group majors into 10 categories: business, liberal arts, economics, non-economics social science, STEM, agriculture, communications, health, undeclared, and other.

Both the K-12 and postsecondary records are linked to quarterly earnings data from the Texas Workforce Commission (TWC) from 2008 through 2016. The TWC is the administrator of the state's unemployment insurance program. Since these data are the same data used to determine unemployment insurance eligibility and tax bills for employers, they constitute a highly reliable measure of earnings. However, an individual must work in the State of Texas for an employer other than the federal government to be included in the data. Our earnings measures follow those outlined in Andrews, Li and Lovenheim (2016) and Andrews, Imberman and Lovenheim (2016) using the same quarterly earnings data in Texas. We first exclude the top $0.5 \%$ of earnings, which corresponds to $\$ 95,928$ in a quarter. The top $0.5 \%$ of earnings are excluded because of the long right tail of the earnings distribution that dominates the data. We then take the natural logarithm of earnings measured 10 or more $(10+)$ or 12 or more $(12+)$ years after high school graduation. Finally, we de-mean this restricted log quarterly earnings measure by year-quarter-high school graduation cohort means and average the residuals over the relevant time periods within individuals. This creates a single log earnings measure for each individual that is net of the interaction of year, season, and high school cohort effects. In our preferred model, we restrict to individuals with at least 5 quarters of positive earnings during the specificized time frame in order to measure earnings among full-time workers that are likely more reflective of lifetime earnings. We find no evidence that the GPA discontinuity leads to selection into this earnings sample, which supports this approach. Nonetheless, we provide estimates without the five quarter restriction as well.

Our analysis focuses on students who are first-time college enrollees in a four-year public 
institution in the 1999-2008 entry cohorts and who graduated from a public Texas high school. We restrict our attention to these cohorts because we do not have consistent college GPA data prior to 2000 and because we need to allow students sufficient time to finish college and enter the workforce to measure several of our outcomes of interest. Table 1 contains summary statistics for our analysis sample, which further restricts to institutions and cohorts with GPA cutoffs as well as our preferred RD bandwidth (0.75 grade points below and 0.5 grade points above the cutoff). Details on how we identify these cutoffs are provided below.

The table shows tabulations for three groups: all students, those whose final major is business, and those with a different final major. Business majors in the analysis sample have lower high school test scores than non-business majors and they are more likely to be male. This demonstrates the selection problem that our empirical analysis seeks to solve: those sorting into business majors have different underlying abilities from students in other majors, only some of which are observed. Despite the lower pre-collegiate ability level of business majors, they earn more $10+$ and $12+$ years after college entry than their counterparts in non-business majors and they have lower graduate school attendance.7 They do, however, have similar graduation rates. Finally, column (7) demonstrates that business majors are popular in the analysis sample; $9 \%$ of students have a final major of business, despite the fact that many of them are academically ineligible to major in business and the sample is restricted to those who are not in business upon entry into college. Among the full sample of Texas students, $16 \%$ have a final major in business.

\section{Empirical Methodology}

\subsection{Measuring GPA Cutoffs for Business Transfers}

To overcome the biases from selection into business majors based on students' unobserved characteristics, we exploit the use of grade minima for students who wish to switch to business. In

\footnotetext{
${ }^{7}$ We can only observe if a student attends graduate school at a public Texas institution. Despite missing out-of-state graduate enrollment, we believe this measure is informative because in-state graduate school is much less expensive for these students and there is little reason to believe switching majors would generate systematic changes in the state where the student attends graduate school.
} 
the US, while most universities have general admission criteria, certain fields within a university impose additional requirements. This is commonly found in fields such as business and other undergraduate professional schools where the requirements facilitate capacity control. There are many ways in which the major can be restricted to students. In some cases, students are required to meet minimum SAT or ACT scores upon admission to the university or have a minimum high school GPA. Students who switch into a major while already enrolled at a university (either from another major, from being undeclared, or upon advancing to an upper level of a major) often must show competence in a set of prerequisite courses and/or overall competence through cumulative GPA requirements. It is this last requirement on which our analysis focuses. While the use of admission requirements also provides a potential avenue for identification, the data available to us does not permit us to exploit these discontinuities 8 The UTD-ERC data do not include specific course records for students, so we are not able to identify potential major switchers who take pre-requisite courses nor can we observe grades in those courses. Thus, we exploit minimum cumulative college GPA requirements for students who want to switch into the business major, which is the major in Texas for which there is the most excess demand and for which these GPA rules have historically been employed to regulate major size at several institutions $9^{9}$

We identify the impacts of choosing an undergraduate business major by comparing students in the same institution who barely meet the cumulative GPA requirement set by a field to those who barely miss that requirement in a regression discontinuity framework. ${ }^{10}$ Since institutions do not report student GPA used for these requirements directly, we calculate our own measure of GPA by dividing the cumulative grade points earned as of each semester by the cumulative

\footnotetext{
${ }^{8}$ Such admission rules are common in Europe and South America and are used by Kirkebøen, Leuven and Mogstad (2016) and Hastings, Neilson and Zimmerman (2013) to estimate the return to college major in Norway and Chile, respectively.

${ }^{9}$ We explored the potential for this strategy for many major fields. However, only business school cutoffs were observed in a sufficiently large number of cohorts and institutions to provide reasonable precision for the estimates. There was little systematic evidence of GPA cutoffs for other majors that would allow us to use this approach to estimate earnings effects for other majors. While this limits the majors we can examine to business, it has the benefit that there are not other major access discontinuities at the same place in the GPA distribution that would complicate the interpretation of our estimates.

${ }^{10}$ An alternative strategy would be to utilize admission requirements for specific fields upon entry to college, such as minimum SAT or ACT scores or high school GPA. While promising, our data provide only limited ability to do this as we do not have access to high school GPA, and the cohorts for which we have SAT and ACT scores are limited to only $2004-2008$.
} 
number of credits attempted as of that semester. We make a series of sample restrictions designed to reduce any resulting measurement error in the assignment variable. First, we restrict to first-time, four-year (FTFY) college attendees. This restriction excludes transfer students who begin college in a public two-year school. The difficulty that arises from including two-year transfer students is that the institutions do not report in the data which credits are accepted for transfer. Hence, including these transfers increases the risk that we would be including credits that do not go towards the calculation of GPA used to admit students to the field. Importantly, we do not exclude FTFY students who transfer later in their postsecondary careers, since transferring could be a treatment effect of selecting a particular major. Indeed, we examine this effect directly in our results below. For each student, we use the calculated GPA thresholds for the institution and cohort in which the student first enrolled. The second sample restriction is to include only students who have not declared for a business major in their first semester of enrollment. Students who are declared business majors upon admission are often exempted from the cumulative GPA requirement.

Institutions generally provide multiple opportunities for students to exceed the thresholds and declare majors, generating a range of completed credit hours during which students may change majors. These are highlighted in Table 2, which shows the published requirements for the institutions we use in this analysis. In most cases, there is a minimum number of credits that must be attempted and, sometimes, strict timing requirements (e.g., a student cannot declare after a certain semester) or a maximum number of credits that can be obtained to remain eligible to declare a business major. This flexibility generates two main concerns. First, it increases the likelihood of measurement error as we cannot precisely say at what point in a student's time at an institution the GPA requirement becomes binding. Second, it gives students an opportunity to "game" the threshold by timing their application to match the GPA requirements. To maximize power while also minimizing the risk of the second concern, we use the highest cumulative GPA a student has at any point in his or her $2^{\text {nd }}$ through $4^{\text {th }}$ semesters enrolled in a four-year public institution in Texas as the running variable.

While this method of structuring the running variable largely removes the risk from students gaming the timing of application by basing the forcing variable on whether a student ever 
exceeds the threshold during the period in which he is eligible to switch majors, there remains the risk that students will try to manipulate their cumulative GPA through more direct means. Examples of such behavior are altering effort or changing course-taking behavior. This is the main threat to the validity of our empirical design. We show below through the use of balance tests and observations of the density of the GPA distribution around the threshold that there is no evidence of such manipulation. Furthermore, there are a number of reasons why such attempts at manipulation likely would not invalidate our identification strategy. First, a popular strategy among students may be to take easier courses to help ensure that they will get a higher grade. While this is probably quite common, students need to be able to precisely earn a specific grade if they are near a threshold, which is a much harder endeavor. That is, it is likely that students who both barely exceed and do not exceed thresholds have the same course taking strategy and put forth the same effort, but one student performs slightly worse in the class than expected (or vice versa). A second possibility is that students take classes but drop them if their grade falls below that needed for the threshold. In general, students cannot drop a class beyond the first third of a semester, and thus they will not know what their final grade would have been in the absence of dropping. The key to both of these concerns is that there remains a level of exogenous variation in final grades regardless of students' abilities to make adjustments on the effort, course selection, and course dropping margins. That is, our running variable is imperfectly manipulable. Lee (2008) shows that imperfect manipulability of the running variable produces the local randomization that is key to the regression discontinuity design. Using standard tests, we provide evidence that our running variable is imperfectly manipulable.

A final concern that represents a more straightforward manipulation mechanism is that students could simply request that professors change their grades if they do not meet the cutoff. Such requests are quite common in general and it is indeed likely that professors would use factors unobserved to the econometrician to determine who receives the grade increases. While we cannot rule out that such manipulation occurs, our balance and density tests indicate that any impact on our estimates is likely negligible.

To conduct this analysis, we need precise measures of the GPA cutoffs used at each insti- 
tution and in each year. Ideally, these cutoffs would all be published, and we would know for which students each cutoff applies. Unfortunately, information on specific GPA requirements is not consistently published, which makes determining cutoffs more complex. While in many cases cutoffs are published either in a catalogue or on the department's website, these typically are only available for current students. Examples of these cutoffs can be seen in the second to last column of Table 2.11 Given that the students in our analysis would have been applying for the change in major 7 to 13 years prior and that it is common for cutoffs to change over time to reflect major demand and department resources, the published current cutoffs differ from the earlier cutoffs faced by the cohorts we analyze. In some cases, the cutoffs may not be published at all but still may exist. This can occur because the department never actually published the cutoff being used or because they effectively used a cutoff that was not part of a formal policy but was used as a way to regulate excess demand in a given year. Additionally, there are some differences between institutional GPA calculations and our GPA calculation due to rounding errors or the exclusion of certain courses like remedial classes from the GPA calculation. Finally, since students in the same entry cohort may face different cutoffs based on the year in which they apply for the major (recall that we use the $2^{\text {nd }}$ through $4^{\text {th }}$ semester enrolled and some students may have gaps in their enrollment) students in the same entry cohort may face slightly different cutoffs.

Given these challenges with measuring cutoffs, we implement a procedure similar in spirit to that used by Goodman, Hurwitz and Smith (2015) to identify "hidden" admission thresholds for college admission via SAT score thresholds and Hoekstra (2009) for entry into a flagship university $\sqrt{12}$ For each institution and entering cohort in Texas from 1999-2008, we estimate the

\footnotetext{
${ }^{11}$ A key exception here is business school requirements for University of Texas at Austin, which are available on their website back to 2004. We cross-checked our empirically identified cutoffs for the 2002 to 2005 college entry cohorts with published rules two years later. The observed thresholds were very close to the published thresholds - no more than 0.2 grade points away.

${ }^{12}$ Goodman, Hurwitz and Smith (2015) use a data-driven procedure that formally tests for discontinuities at various SAT scores for many institutions, limiting their analysis to the few institutions where discontinuities are estimated with t-statistics greater than 3 . Hoekstra uses a similar procedure and chooses the discontinuity that provides the highest $R^{2}$. We follow a procedure more similar to Goodman, Hurwitz and Smith (2015) because, as in their setting, we are not sure whether a cutoff rule exists in a given institution during a given year.
} 
following regression discontinuity model:

$$
1(\text { Business })_{i}=\beta_{0}+\beta_{1} 1\left(G P A \geq G P A^{\prime}\right)_{i}+\beta_{2} G P A_{i}+\beta_{3} 1\left(G P A \geq G P A^{\prime}\right)_{i} \times G P A_{i}+\varepsilon_{i}
$$

where 1 (Business) is an indicator for whether the student's final major is business, GPA is the student's maximum GPA over his/her $2^{\text {nd }}$ to $4^{\text {th }}$ semester as defined above, and GPA' is the proposed GPA cutoff for transferring into a business major. The model is estimated separately by institution and cohort, where the cutoffs are set at GPA levels between 2.5 and 3.65 (the highest published cutoff at UT-Austin) in 0.05 grade point increments. Each regression is restricted to students who are not declared business majors in their first semester with MaxGPA above 2.013

After the model is estimated, we collect the cutoff for each institution-cohort with the largest t-statistic for $\beta_{1}$ given that t-statistic is at least 2.5.14 Finally, as a double check on this empirically driven approach, we visually inspected figures that plot mean GPAs within 0.1 point bins for each institution-cohort to confirm the existence of discontinuities determined by the strategy just described. In no case did we discard a cutoff chosen through the empirical procedure due to the failure to visually observe a sufficient jump in business majors at the identified cutoff.

Through this procedure, we identified thresholds at five institutions: UT-Austin, Texas A\&M, Texas Tech, University of Houston, and UT-Arlington. The empirically-determined cutoffs are highlighted in Table 2, with the published rules for 2015 provided for comparison. In general, the empirically determined cutoffs for 1999 - 2008 are close to the published cutoffs used in 2015. This is particularly true for UT-Austin and Texas A\&M, which contain most of the cohorts with cutoffs. Exact cutoffs for each year and institution are shown in Table 3, along with the size of the estimated discontinuity and the t-statistic of the test of the null hypothesis

\footnotetext{
${ }^{13}$ We restrict to students with GPAs above 2.0 to avoid including students on academic probation.

${ }^{14}$ We conducted a similar exercise for communications, engineering, physical sciences, social sciences, biology, economics, agriculture, and computer science. While published cutoffs exist for many sciences and engineering programs, the rates of switching into these majors are very low. Hence, we did not find consistent evidence of GPA cutoffs being used for these majors or any of the others tested besides business. Thus, business appears to be the only major for which GPA cutoffs are used to regulate demand in Texas. That these cutoffs do not exist for other majors also suggests we are not measuring some mechanical effect related to the likelihood of majoring in a given subject and GPA.
} 
of no discontinuity. Online Appendix Figures A-4 through A-8 show plots for each of these institutions and cohorts while Appendix Figure A-9 shows the t-statistic for each cohort in these institutions, highlighting those that fall above 2.5. For UT-Austin and Texas A\&M, we are able to identify cutoffs in each year except 2005 for TAMU. In Texas Tech, University of Houston, and UT-Arlington, only a handful of cohorts have cutoffs and these are mostly early cohorts. This either occurs because the cutoffs are only used when there is excess demand - it is likely demand was lower than expected in the other years, which led to nonenforcement of any GPA cutoff rule - or there are simply not enough marginal students who wish to change majors to generate a detectable effect. Nonetheless, these cutoffs imply that our estimates will be weighted towards the two flagship institutions, so the local average treatment effects should be interpreted in this context. Our results mostly reflect returns for the more elite public institutions. We also provide estimates using samples restricted to the flagships to formalize this feature of our empirical design.

\subsection{Regression Discontinuity Model}

Using the discontinuities shown in Table 3, we estimate the following linear probability models on the analysis sample described above to identify the effect of the admission thresholds on the distribution of majors:

$$
\begin{aligned}
1\left(\text { Major }_{i}=\text { Major }_{k}\right)_{i j c}= & \alpha_{0}+\alpha_{1} 1\left(G P A_{i} \geq G P A_{j c}^{\prime}\right)+f\left(G P A_{i} ; \gamma\right) \\
& +1\left(G P A_{i} \geq G P A_{j c}^{\prime}\right) * f\left(G P A_{i} ; \delta\right)+\Omega \boldsymbol{X}_{\boldsymbol{i}}+\mu_{j c}+\varepsilon_{i j c}
\end{aligned}
$$

where Major $_{i}$ is the final major and Major $_{k}$ is one of the ten major categories listed in Table 1 (including business), GPAi is the student's cumulative GPA as defined above, GPA $A_{j c}^{\prime}$ is the cutoff for business in institution $j$ for student entry cohort $c$, and $f($.$) is a polynomial$ in maximum GPA in semesters 2-4. Our preferred method uses a quadratic polynomial in the running variable, but we also show estimates using linear and cubic polynomials. The vector $\mu_{j c}$ is a set of institution-cohort fixed effects, and $\Omega X_{i}$ is the set of observed student characteristics

shown in Table 1 as well as student race/ethnicity indicators. The observables and fixed effects 
are included to improve precision, but estimates without them are very similar. We show results that use bandwidths of $(-0.5,0.5),(-0.75,0.5)$ and $(-1.0,0.5)$ grade points. Because of where the cutoffs are located, observations more than 0.5 GPA points above the cutoff come from schools where the cutoffs are lower, which introduces concerns about sample composition across the distribution of the running variable. For this reason, we do not increase the bandwidth above the cutoff. As we show below, our results are insensitive to the specific bandwidth used.

The coefficient of interest in equation (2) is $\alpha_{1}$. When $k=$ business, $\alpha_{1}$ is the first stage estimate. When $k \neq$ business, $\alpha_{1}$ shows how the GPA cutoff affects the likelihood of majoring in other subjects. Thus, we are able to determine not only how these cutoff rules affect business majoring but also the distribution of majors from which the marginal business majors are drawn. This allows us to clearly specify the distribution of counterfactual majors for students at the thresholds, which are critical in interpreting the estimated effects of majoring in business on outcomes. Unlike the OLS estimates that are common in the literature, the RD results show how outcomes change due to being permitted to major in business relative to a student's second choice major. From a policy perspective, this is an extremely important parameter because it shows the effect of choosing business relative to each student's most likely alternative. While comparisons among majors such as business and English are interesting, if few students are on the margin of choosing between them, the comparison is less informative. Rather, we want to know what the effect of choosing a given major is relative to the other likely majors in a student's choice set. This is the parameter identified by our RD framework.

To estimate the impacts of major choice on attainment and earnings, we estimate reducedform models and "fuzzy RD" models that use the cutoff itself as an instrument for field choice. The reduced form model is:

$$
\begin{aligned}
Y_{i j c}= & \pi_{0}+\pi_{1} 1\left(G P A_{i} \geq G P A_{k j c}^{\prime}\right)+f\left(G P A_{i} ; \gamma\right)+1\left(G P A_{i} \geq G P A_{j c}^{\prime}\right) * f\left(G P A_{i} ; \delta\right) \\
& +\boldsymbol{\Omega} \boldsymbol{X}_{\boldsymbol{i}}+\mu_{j c}+\varepsilon_{i j c},
\end{aligned}
$$

where $Y_{i j c}$ is the set of education and labor market outcomes discussed in Section 2. All other variables in the model are as previously defined; $\pi_{1}$ is the estimate of the impact of exceeding 
the GPA threshold on the various outcomes we examine in this analysis, and it is the parameter of interest in this model.

For the fuzzy RD models, we estimate equation (2) with $k=$ business as the first-stage model and then estimate the following second stage model:

$$
Y_{i j c}=\beta_{0}+\beta_{1} \text { Business } s_{i j c}+f\left(G P A_{i} ; \gamma\right)+1\left(G P A_{i} \geq G P A_{j c}^{\prime}\right) * f\left(G P A_{i} ; \delta\right)+\boldsymbol{\Omega} \boldsymbol{X}_{i}+\mu_{j c}+\varepsilon_{i j c}
$$

where Business $s_{i}$ is the predicted probability that the student $i$ 's final major will be business, calculated using the estimates from equation (2).

The identification assumption underlying our empirical approach is that students cannot manipulate their GPAs precisely so as to decide whether or not they exceed a threshold within a small neighborhood of the threshold. That is, student characteristics (both observed and unobserved) need to move smoothly through the thresholds. Using the rich set of observed characteristics of students from the K-12 data, we can test this assumption by examining whether student characteristics including, crucially, pre-college test scores, change at the discontinuities. Estimates of $\pi_{1}$ from equation (3) using various observed pre-determined characteristics as the dependent variable are shown in Table 4. We present results from models that use a quadratic spline in the running variable and a bandwidth of 0.75 GPA points below the cutoffs and 0.5 above the cutoffs 15 We show results both with and without postsecondary institution-cohort fixed effects. The dependent variables include pre-collegiate academic achievement measures such as Texas standardized test scores and SAT/ACT scores, demographic characteristics, and socioeconomic characteristics. The coefficients are universally close to zero and almost none is statistically significant. One estimate (SAT math with fixed effects) is significant at the $10 \%$ level and gifted status in high school is significant at the $1 \%$ level in both models. Even so, the point estimates on these estimates are small and negative. Hence they work against our findings that business majors right above the cutoff earn more in the labor market. These results are inconsistent with student sorting around the threshold in a manner that would generate

\footnotetext{
${ }^{15}$ Estimates for alternative bandwidths and specification of the running variable are similar in magnitude and statistical significance.
} 
positive selection and provide strong support for the validity of our approach.

We also examine whether there is bunching in the density of the underlying distributions of students at the threshold, which would indicate GPA manipulation (McCrary, 2008). Figure 1 contains GPA densities that have been rescaled such that they are relative to the cutoffs at each institution and in each year. This distribution is at its peak around the cutoffs, which is a function of where the departments decide to locate the thresholds. However, there is no evidence of bunching above the cutoffs. Together, Figure 1 and Table 4 suggest there is no manipulation of the running variable in an area local to the major GPA cutoffs $\sqrt{16}$

\section{Results}

\subsection{First Stage Estimates}

Figure 2 and Table 5 provides estimation results for the first stage impact of exceeding a cutoff for business major access on majoring in business. There is an increase in majoring in business of about 0.05 at the threshold that varies little with the bandwidth. The estimates are affected little by the addition of background controls and institution-cohort fixed effects as well, and they are highly statistically significant (t-statistics are in excess of 10). Figure 2 presents compelling visual evidence of an increase in the likelihood of having a final major in business as a function of the GPA cutoffs. While we include quadratic smoothers and a vertical line at cutoff, the discontinuity would be evident from the raw plot of means. Figure 2 shows that the likelihood of majoring in business right below the threshold is about $7 \%$, so there is a $71 \%$ increase in the likelihood of majoring in business at the GPA discontinuity.

In order to interpret any effects of this shift in major choice on outcomes, it is important to identify what majors students would have chosen if they had not been able to select business. That is, we want to know what the counterfactual "second-choice" majors are for the compliers. We estimate the effect of being given access to the business major relative to one's second major choice using equation (2). This is an important parameter of interest, as it shows the effect of

\footnotetext{
${ }^{16} \mathrm{~A}$ formal density test at the discontinuity with a bin size of 0.05 provides an estimate of 0.029 (se 0.018 ). A figure showing the results of this test is provided in Appendix Figure A-1
} 
capacity restrictions on the distribution of final majors. This parameter differs from one that compares average outcomes across two majors, where in actuality few students may be deciding between two particular fields (e.g., arts and humanities vs. engineering).

We estimate the counterfactual distribution of majors by setting up a series of linear probability models as in equation (2) but with the dependent variable being a major other than business. The sum of the $\alpha_{1}$ coefficients in these regressions should equal the negative of the $\alpha_{1}$ coefficient in equation (2) when the business major is the dependent variable. These estimates all use a quadratic spline in the running variable and include institution-cohort fixed-effects. Results are shown in Table 6. The first two rows for each bandwidth show the estimates of the effect of being above the GPA cutoffs on majoring in the given field. The third row shows what percent of the increase in the business major comes from this field. This is calculated as the negative of the ratio of the effect on the given major to the effect on majoring in business. Note that since we estimate separate models for each outcome there are no cross-model parameter restrictions on the estimates. As a result, the sum of the counterfactual major effects does not exactly equal the negative of the business major effect. We rescale the counterfactuals to sum to $100 \%$ in order to account for this problem.

Table 6 shows that about $60 \%$ of the students who gain access to business because of the GPA rules would have majored in STEM. The rest of the majors outside of undeclared and communications each form similar-sized components of the counterfactual. Online Appendix Figure A-2 presents RD figures for each of these majors. While Table 6 shows that the counterfactual for the marginal business students is a mix of alternative majors, GPA cutoffs largely act to shift students out of STEM and Economics and into business. The second stage estimates will be relative to this mix of counterfactual majors.

Of note in Table 6 is the large positive effect on majoring in communications. Panel (f) of Online Appendix Figure A-2 shows that this effect is driven completely by one outlier point right at the discontinuity. This effect does not survive a donut analysis, provided in Appendix Table A-1, in which we exclude observations proximate to the threshold. Our main results remain when we do this analysis, as shown in Online Appendix Table A-5. This suggests that our estimates are not being driven by the jump in the likelihood of majoring in communications 
at the GPA cutoff.

\subsection{Effects on Postsecondary and Labor Market Outcomes}

Table 7 shows estimates of the effect of majoring in business on educational outcomes. Although none of the estimates is statistically significantly different from zero at even the $10 \%$ level, the graduation likelihood effects are positive and non-trivial in magnitude. Estimates using our preferred bandwidth of $(-0.75,0.5)$ indicate that majoring in business increases the likelihood of graduating in 6 years by 18 percentage points and in 8 years by 12 percentage points. Figure 3 shows RD plots for the 6-year graduation rate. There is a clear visual discontinuity at the GPA cutoff. Online Appendix Figure A-3 shows similar plots for 4- and 8-year graduation rates. Consistent with Table 7, there is no evidence of an effect for 4-year graduation but there is for graduation within 8 years.

We do not see any effect of majoring in business on attending a public graduate school in Texas, but business majors are less likely to transfer. The transfer result, though not statistically significant, probably reflects the fact that these students are able to select their first-choice major, which reduces the incentive to transfer institutions. Figure A-3 shows visual evidence that aligns strongly with results in Table 7 . Taken together, the results in Table 7 suggest that majoring in business due to passing a GPA threshold has a positive effect on postsecondary attainment.

In Table 8, we present RD estimates of the effect of choosing a business major on earnings $10+$ and $12+$ years after first enrolling in college ${ }^{17}$ We show estimates using all three bandwidths with no controls (columns 1 and 4), with institution-cohort fixed effects (columns 2 and 5) and with institution-cohort fixed effects as well as observed characteristics (columns 3 and 6). Our earnings measures are adjusted log earnings as described in Section 2, and we show results restricted to workers with at least five quarters of positive earnings and to workers with at least one quarter of positive earnings. The estimates are remarkably consistent across specifications: using our preferred earnings measure in columns (1-3), 10+ year earnings increase by 0.36 -

\footnotetext{
${ }^{17}$ Online Appendix Table A-2 presents reduced form estimates of the effect of passing the GPA threshold on earnings.
} 
$0.43 \log$ points, or $43 \%$ - $54 \%$, and $12+$ year earnings increase by $0.60-0.82 \log$ points, or $82 \%-127 \%$. Figure 4 presents visual evidence of the discontinuity in earnings as well. Point estimates from specifications using all earnings observations are similar in magnitude to those using the five-quarter earning sample but are much less precisely estimated. This is because we are adding a lot of variation in the dependent variable (and thus in the error term) that is uncorrelated with whether students select a business major. The exclusion of this extraneous earnings variation that is unlikely to be indicative of lifetime earnings is a main argument for restricting the analysis to those with five quarters of earnings.

The results in Table 8 also suggest that the returns to business major grow with potential experience. The estimates for $12+$ years are universally larger than the estimates for $10+$ years, although they tend not to be statistically different. In our preferred specification, the effects almost double across earnings time periods. This is at least suggestive evidence that the returns to business majors reflect human capital differences rather than signaling, as signaling effects should diminish rather than strengthen as workers gain experience and employers directly observe their productivity.

One of the concerns with using administrative earnings data from one state is selection into the earnings sample. Such selection comes from two sources: individuals who do not work (or who have fewer than five quarters of earnings) and individuals who work out of state. Neither group is included in our earnings measures. If being a business major increases in-Texas labor force participation, then the RD estimates can be biased by the changing composition of earners at the cutoff. Online Appendix Table A-3 shows IV estimates in which the dependent variable is the likelihood an individual is observed in the earnings data. There is no statistically significant evidence that being induced to major in business by passing a GPA cutoff is associated with changes in the likelihood of being in the earnings sample. Furthermore, the estimates are generally small in magnitude. This evidence suggests that our earnings estimates are not being driven or heavily influenced by changes in the composition of earners around the GPA cutoffs. 


\subsection{Comparison with OLS Estimates}

The estimates in Table 8 point to large effects of majoring in business on earnings. One of the motivations for using an $\mathrm{RD}$ approach to estimate the return to business majors is concerns related to selection on unobservables in the OLS models. It thus is useful to compare our results to those one would obtain from an OLS model that controls for the rich set of student background, academic achievement and institution-cohort fixed effects available in our data. These estimates contain a broader set of controls than prior work using selection-onunobservables methods, so they are a good point of comparison with respect to what one might find using state-of-the-art OLS techniques.

A core difficulty in comparing the OLS and IV estimates is that the RD estimates represent a local average treatment effect for students on the margin of being academically eligible for the major and the OLS estimates show average treatment effects. In order to reduce differences in the estimates driven by heterogeneous treatment effects, we estimate OLS models that control for the student characteristics in Table 1 and institution-cohort fixed effects on the RD sample. To do this, we only use the RD cohorts and institutions, and we limit our sample to those in the $(-0.75,0.5)$ bandwidths. These estimates are shown in Table 9 . In the top panel, we estimate the effect of each major category relative to business majors, and in the bottom panel we estimate the average difference between business majors and all other majors. Adjusted for students observed characteristics, business students earn more than those in other majors, although the estimates are far smaller than the RD results. Business majors also are more likely to graduate and to transfer ${ }^{18}$

It is quite difficult to compare the OLS estimates in Table 9 to the RD estimates in Table 7 and 8 because the mix of counterfactual majors is different across the two estimates. Table 6 shows the distribution of comparison majors for the RD models, while column (7) of Table 1 shows the same for the OLS estimates. Thus, while $60 \%$ of the counterfactual is comprised of STEM majors and $9 \%$ is comprised of Economics majors in the RD estimates, in the OLS

\footnotetext{
${ }^{18}$ Online Appendix Table A-4 shows OLS estimates for the full sample of institutions, cohorts and students in Texas. The estimates are quite similar to those in Table 9, suggesting that the OLS estimates in the RD sample are more broadly applicable. Additionally, these estimates are consistent with OLS results in prior selection-on-observable studies, making comparisons with the IV results particularly useful.
} 
results these majors only comprise $26.3 \%$ and $2.1 \%$ of the counterfactual, respectively. To align the distribution of counterfactuals, we take the counterfactual ratios estimated in Table 6 and apply them to the coefficient estimates in the top panel of Table 9. That is, we essentially reweight OLS by the implicit IV weights related to each counterfactual major (Angrist, Graddy and Imbens 2000), such that the models do not differ in the distribution of majors selected by non-business students. Specifically, we estimate:

$$
R_{B}=\sum_{k} \frac{-\alpha_{1, k}}{\alpha_{1, B}} \times \beta_{k}
$$

where $\alpha_{1, k}$ is the parameter estimate from equation (2) with an indicator for major $k$ as the dependent variable, $\alpha_{1, B}$ is the parameter estimate from equation (2) with an indicator for business major as the dependent variable, and $\beta_{k}$ is the OLS estimate of the effect of major $k$ relative to business on a given outcome. Equation (5) shows that the estimated return to business for a given mix of counterfactual majors is a weighted average of the OLS estimated outcome difference between business and each major $\left(\beta_{k}\right)$ weighted by the proportion of the counterfactual constituted by each major $\left(\frac{-\alpha_{1, k}}{\alpha_{1, B}}\right) .19$

The implied effects of majoring in business on educational attainment from calculating equation (5) is similar to the IV estimates, but this is not the case for earnings. The OLS results with the RD counterfactual mix predict a six-year graduation effect of $9.7 \%$ and an eight-year graduation effect of $11.0 \%$. These are similar to the estimates in Table 7 , though somewhat smaller. However, equation (5) predicts earnings effects of $-1.4 \%$ for both the $10+$ and $12+$ earnings measures. Looking at Table 9 , it is clear why this is the case: most marginal business majors in the RD model are drawn from majors with higher earnings returns according to the OLS model. This stands in stark contrast to what the RD estimates predict.

Why might the OLS and RD estimators yield such different estimates of the effects of choosing a business major on labor market outcomes? Table 1 shows that business majors in the RD sample have lower pre-collegiate academic achievement. If business students have

\footnotetext{
${ }^{19}$ As discussed above, the sum of the $-\alpha_{1, k}$ estimates does not exactly equal $\alpha_{1, B}$ because we allow the coefficients on other variables (including the running variables) to vary across specifications. That is, we do not impose the restriction that $\sum_{k}-\alpha_{1, k}=\alpha_{1, B}$. We rescale the $\alpha_{1, k}$ to force the counterfactual weights to sum to 1 , but in practice this has little effect on the results or conclusions.
} 
unobserved attributes that are negatively correlated with earnings as well, then this could lead OLS estimates to be lower than RD estimates. However, this would likely cause the graduation results to be biased in similar ways, which is in contrast to what we find. We believe the estimates are most consistent with selection into business majors based on comparative advantage, similar to what is found by Kirkebøen, Leuven and Mogstad (2016) in Norway. ${ }^{20}$ They show that students typically have a higher return to their first-choice major than their second-choice major. The same pattern holds in Texas: students who are able to major in business because they barely qualify for admission to the major have much higher returns than similar students who have to select their second-choice major below the cutoff. This effect is larger in our estimates than in Kirkebøen, Leuven and Mogstad (2016), which we argue is sensible for two reasons. First, the compliers in our study are making major choices mostly in their second year of college rather than in high school, so they likely know more about their own preferences and talents than high school seniors. Second, the earnings distribution is more dispersed in the US than in Norway, so the return to selecting into a field that is a good match may be much higher.

\subsection{Heterogeneous Treatment Effects}

Figure 5 shows the reduced form earnings impacts from crossing the GPA threshold with no controls or fixed-effects by gender. Once the data are separated by gender it becomes clear that the earnings impacts entirely come from women. Women see a noticeable discontinuity in earnings while there is virtually no change for males. The first two rows of Table 10 provide estimates by gender for our outcomes of interest. While the first stage estimates differ little across genders, the differences in the second stage are stark. Among men, there is a statistically significant increase in 6-year graduation, about half of which comes from a reduction in timeto-degree (as the 8-year graduation increase is half the size). Men are also less likely to transfer when they major in business. On the other hand, the earnings effects of selecting a business major are driven almost completely by women. Earnings among women who major in business

\footnotetext{
${ }^{20}$ If sorting into business is based on comparative advantage in the labor market, we would expect the bias with respect to labor market outcomes to be larger than the bias for educational outcomes, which is what we find.
} 
because they pass the GPA cutoff are $1.4 \log$ points higher $12+$ years after college entry, which is a very large effect. From a policy perspective, this is an important finding because of the large policy interest in increasing female participation in STEM and Economics that has arisen. At least for this sample, the returns to business are far higher than the returns to these other majors ${ }^{21}$ This is a hurdle to increasing female participation in these majors, to the extent these policies are aimed at inducing women to select majors that have lower labor market returns.

Because such a large proportion of compliers come from STEM fields, we estimate effects by whether students' first major was STEM in row (3) of Table 10. All of the effects are driven by the subset of students who begin college in a STEM field. Earnings increase $12+$ years postcollege entry by 1.6 log points, and 6-year graduation increases by 51 percentage points. While the impacts may seem large, it is likely these students were struggling in their STEM majors and hence would likely have a strong comparative disadvantage in terms of both completion and labor market outcomes.

Finally in row (4) of Table 10, we estimate effects for students at UT-Austin and Texas A\&M. As Table 3 shows, this sample comprises most of our analysis group. Further, this sample is of interest because they are attending the elite postsecondary institutions in the state, and there is little evidence on how institutional quality and major effects interact. The earnings effects are slightly larger than in the full sample, with a $12+$ earnings increase of 0.94 log points. The graduation estimates are also larger than in the full sample, though as in Table 8 they are not statistically significant. We also find a marginally significant decline in the likelihood of transferring. These results provide suggestive evidence that the returns to business are higher at more-selective institutions, which is interesting because the control groups attend the same selective schools. Nonetheless, we lack the statistical power to provide more than suggestive evidence on heterogeneity in the returns to business by postsecondary institution quality.

\subsection{Robustness Checks}

We show several robustness checks that probe the sensitivity of our estimates to core modeling assumptions in Online Appendix Table A-5. Throughout the paper, we have shown estimates

\footnotetext{
${ }^{21}$ Similar to the full sample, about $60 \%$ of the counterfactual majors for women is STEM and $9 \%$ is Economics.
} 
for different bandwidths that demonstrate our results are not being driven by our selection of a particular bandwidth. In Table A-5, we show that we obtain similar results when we use a cubic spline in the running variable rather than a quadratic. We also show estimates for a linear spline. These estimates are much different, indicating little effect of choosing a business major on the outcomes we consider. This is due to the fact that, as the Figures 3-5 and A-3 demonstrate, the linear specification does a poor job of fitting the data. The quadratic fit is far better, which is underscored by the similarity of the results when we include a cubic spline.

As shown in Table 6 and Figure A-2, there is an increase in communications majors at the GPA cutoffs. This appears to be an outlier in the data, however. To determine the extent to which our results reflect the returns to communications, Table A-5 presents donut RD estimates that exclude those with GPAs within 0.1 or 0.05 of each cutoff. We previously showed in Table A-1 that with a donut of 0.1 the positive communications estimate falls and becomes statistically insignificant in the 0.75 and 1.0 bandwidths. In this table we look at how the donut estimates affect outcomes directly. The first stage estimated impacts on majoring in business are similar and the second stage estimates are, if anything, larger than the baseline results. However, they are quite imprecise. Nonetheless, that the point estimates increase when we exclude those proximate to the threshold suggests our baseline results are not being driven by communications majors.

\section{Conclusion}

In this paper, we provide new evidence on the returns to choice of major using administrativelylinked unemployment insurance, K-12 and higher education data from the State of Texas, with a particular focus on the undergraduate business major. This allows us to track earnings of students well after completing their college careers and measure detailed educational attainment outcomes. We identify five public universities in Texas in which GPA minima were in effect that regulated the ability of students to switch into a business major once enrolled. Using these cutoffs, we estimate regression discontinuity models that identify the causal effect of selecting a business major for students who just qualify for the option to take on a business major on 
postsecondary and labor market outcomes. While we focus on only one major - business these are the first US-based estimates of the returns to college major using techniques that can separate student selection effects from causal effects. Furthermore, business is the most popular single major both in Texas and throughout the United States, making it of high interest to study in its own right.

We show that the GPA thresholds employed by the five universities lead to large changes in the likelihood a student majors in business. There is suggestive, albeit statistically insignificant, evidence that majoring in business increases 6- and 8-year graduation rates, and we find that selecting a business major among those at the discontinuity increases earnings 12 or more years after initial enrollment by $127 \%$. Earnings effects are localized to women, while educational attainment effects are localized to men. Additionally, most of the educational and labor market outcome effects are driven by students who first selected a STEM major. The estimated impact of majoring in business on earnings using the RD estimator differs substantially from OLS estimates, even after aligning the distribution of counterfactual majors across estimators. We argue this difference is likely coming from selection of students into majors based on comparative advantage, which is consistent with the OLS and RD estimates aligning more closely for graduation if the sorting is driven by perceived labor market returns. 


\section{References}

[1] Altonji, Joseph G., 1993. "The Demand for and Return to Education When Education Outcomes are Uncertain." Journal of Labor Economics 11(1): 48-83.

[2] Altonji, Joseph G., Peter Arcidiacono and Arnaud Maurel. 2015. "The Analysis of Field Choice in College and Graduate School: Determinants and Wage Effects." NBER Working Paper No. 21655.

[3] Altonji, Joseph G., Erica Blom and Costas Meghir. 2012. "Heterogeneity in Human Capital Investments: High School Curriculum, College Major, and Careers." NBER Working Paper No. 17985 .

[4] Andrews, Rodney J., Jing Li and Michael F. Lovenheim. 2016. "Quantile Treatment Effects of College Quality on Earnings." Journal of Human Resources 51(1): 200-238.

[5] Andrews, Rodney J., Scott A. Imberman and Michael F. Lovenheim. 2016. "Recruiting and Supporting Low-Income, High-Achieving Students at Flagship Universities." NBER Working Paper No. 22260.

[6] Angrist, Joshua D., Kathryn Graddy and Guido W. Imbens. 2000. "The Interpretation of Instrumental Variables Estimators in Simultaneous Equations Models with an Application to the Demand for Fish." Review of Economic Studies 67: 499-527.

[7] Arcidiacono, Peter. 2004. "Ability Sorting and the Returns to College Major." Journal of Econometrics 121(1-2): 343-375.

[8] Arcidiacono, Peter and Cory Koedel. 2014. "Race and College Success: Evidence from Missouri." American Economic Journal: Applied Economics 6(3): 20-57.

[9] Ashenfelter, Orley C. and Alan B. Krueger. 1994. "Estimates of the Economic Returns to Schooling from a New Sample of Twins." American Economic Review 84(5): 1157-1173.

[10] Black, Dan A. and Jeffrey A. Smith. 2004. "How Robust is the Evidence on the Effects of College Quality? Evidence from Matching." Journal of Econometrics 121(1-2): 99-124. 
[11] Black, Dan A. and Jeffrey A. Smith. 2006. "Estimating the Returns to College Quality with Multiple Proxies for Quality." Journal of Labor Economics 24(3): 701-728.

[12] Bound, John, Michael F. Lovenheim and Sarah E. Turner. 2010. "Why Have College Completion Rates Declined? An Analysis of Changing Student Preparation and Collegiate Resources." American Economic Journal: Applied Economics 2(3): 129-157.

[13] Bound, John, Michael F. Lovenheim and Sarah E. Turner. 2012. "Increasing Time to Baccalaureate Degree in the United States." Education Finance and Policy 7(4): 375-424.

[14] Brewer, Dominic J., Eric R. Eide and Ronald G. Ehrenberg. 1999. "Does It Pay to Attend an Elite Private College? Cross-Cohort Evidence on the Effects of College Type on Earnings." Journal of Human Resources 34(1): 104-123.

[15] Card, David. 1995. "Using Geographic Variation in College Proximity to Estimate the Return to Schooling." In L.N. Christofides, E.K. Grant, and R. Swidinsky, editors, Aspects of Labor Market Behaviour: Essays in Honour of John Vanderkamp. Toronto: University of Toronto Press.

[16] Carnevale, Anthony P., Jeff Strohl, and Michelle Melton. 2011. "What's it Worth?: The Economic Value of College Majors." Center on Education and the Workforce, Georgetown University.

[17] Dale, Stacey Berg and Alan B. Krueger. 2002. "Estimating the Payoff to Attending a More Selective College: An Application of Selection on Observables and Unobservables." Quarterly Journal of Economics 117(4): 1491-1527.

[18] Dale, Stacey B. and Alan B. Krueger. 2014. "Estimating the Effects of College Characteristics over the Career Using Administrative Earnings Data." Journal of Human Resources 49(2): 323-358.

[19] Goodman, Joshua, Michael Heurwitz and Jonathan Smith. 2015. "College Access, Initial College Choice, and Degree Completion.” NBER Working Paper No. 20996. 
[20] Grogger, Jeff and Eric Eide. 1995. "Changes in College Skills and the Rise in the College Wage Premium." Journal of Human Resources 30(2): 280-310.

[21] Hastings, Justine S., Christopher A. Neilson, and Seth D. Zimmerman. 2013. "Are some degrees worth more than others? evidence from college admission cutoffs in Chile." NBER Working Paper No. 19241.

[22] Hamermesh, Daniel S. and Stephen G. Donald. 2008. "The Effect of College Curriculum on Earnings: An Affinity Identifier for Non-ignorable Non-response Bias." Journal of Econometrics 144(2): 479-491.

[23] Heckman, James J., Jora Stixrud and Sergio Urzua. 2006. "The Effects of Cognitive and Noncognitive Abilities on Labor Market Outcomes and Social Behavior ." Journal of Labor Economics 24(3): 411-482.

[24] Hershbein, Brad and Melissa Kearney. 2015. "Major Decisions: What Graduates Earn over Their Lifetimes." Hamilton Project Report.

[25] Hoekstra, Mark. 2009. "The Effect of Attending the Flagship State University on Earnings: A Discontinuity-Based Approach." Review of Economics and Statistics 91(4): 717-724.

[26] Hungerford, Thomas and Gary Solon. 1987. "Sheepskin Effects in the Returns to Education." Review of Economics and Statistics 69(1): 175-177.

[27] Jaeger, David A. and Marianne E. Page. 1996. "Degrees Matter: New Evidence on Sheepskin Effects in the Returns to Education." Review of Economics and Statistics 78(4): 733740.

[28] James, Estelle, Nabeel Alsalam, Joseph C. Conaty and Duc-Le To. 1989. "College Quality and Future Earnings: Where Should You Send Your Child to College?" American Economic Review 79(2): 247-252.

[29] Kane, Thomas J. and Cecilia Elena Rouse. 1995. "Labor-Market Returns to Two- and Four-Year College." American Economic Review 85(3): 600-614. 
[30] Keane, Michael P. and Kenneth I. Wolpin. 1997. "The Career Decisions of Young Men." Journal of Political Economy 105(3): 473-522.

[31] Kinsler, Josh and Ronni Pavan. 2015. "The Specificity of General Human Capital: Evidence from College Major Choice." Journal of Labor Economics 33(4): 933-972.

[32] Kirkebøen, Lars, Edwin Leuven and Magne Mogstad. 2016. "Field of Study, Earnings, and Self-Selection." Quarterly Journal of Economics.

[33] Koedel, Cory. 2011. "Grading Standards in Education Departments at Universities." Education Policy Analysis Archives 19(23).

[34] Lee, David. 2008. "Randomized Experiments from Non-Random Selection in U.S. House Elections." Journal of Econometrics 142(2): 675-697

[35] Leppel, Karen. 2001. "The Impact of Major on College Persistence among Freshmen." Higher Education 41(3): 327-342.

[36] Loury, Linda Datcher, and David Garman. 1995. "College Selectivity and Earnings." Journal of Labor Economics 13(2): 289-308.

[37] Rumberger, Russell W. and Scott L. Thomas. 1993. "The Economic Returns to College Major, Quality and Performance: A Multilevel Analysis of Recent Graduates." Economics of Education Review 12(1): 1-19.

[38] McCrary, Justin. 2008. "Manipulation of the Running Variable in the Regression Discontinuity Design: A Density Test." Journal of Econometrics 142(2): 698-714.

[39] St. John, Edward P., Shouping Hu, Ada Simmons, Deborah Faye Carter, and Jeff Weber. 2004. "What Difference Does a Major Make? The Influence of College Major Field on Persistence by African American and White Students." Research in Higher Education 45(3): $209-232$.

[40] Zimmerman, Seth D. 2014. "The Returns to College Admission for Academically Marginal Students." Journal of Labor Economics 32(4): 711-754. 
Figure 1: Distribution of Max GPA Conditional on Non-Business First Major

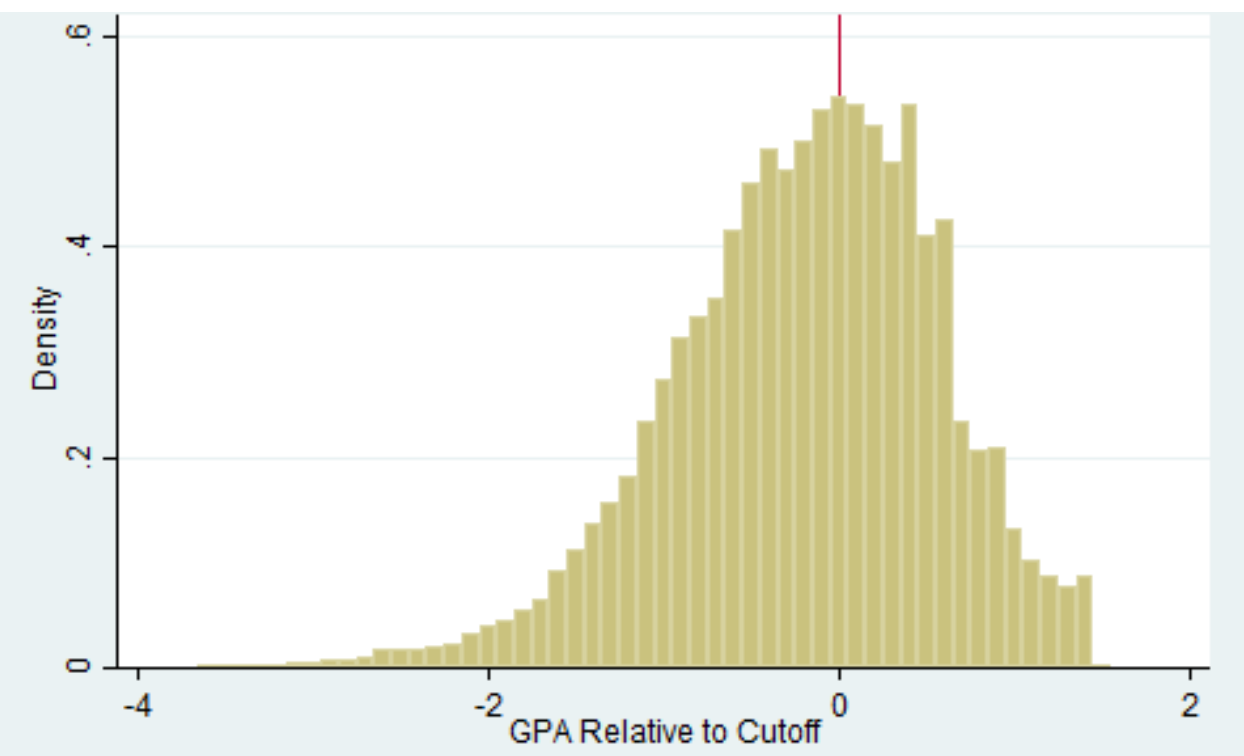

Max GPA is calculated as the maximum cumulative GPA during the $2^{\text {nd }}$ to $4^{\text {th }}$ semesters enrolled. The sample is restricted to Texas residents who enroll as a first-time four-year student in a cohort and institution identified as having a GPA cutoff and who do not select a business major in their $1^{\text {st }}$ semester.

Figure 2: Final Major in Business as Function of Max GPA

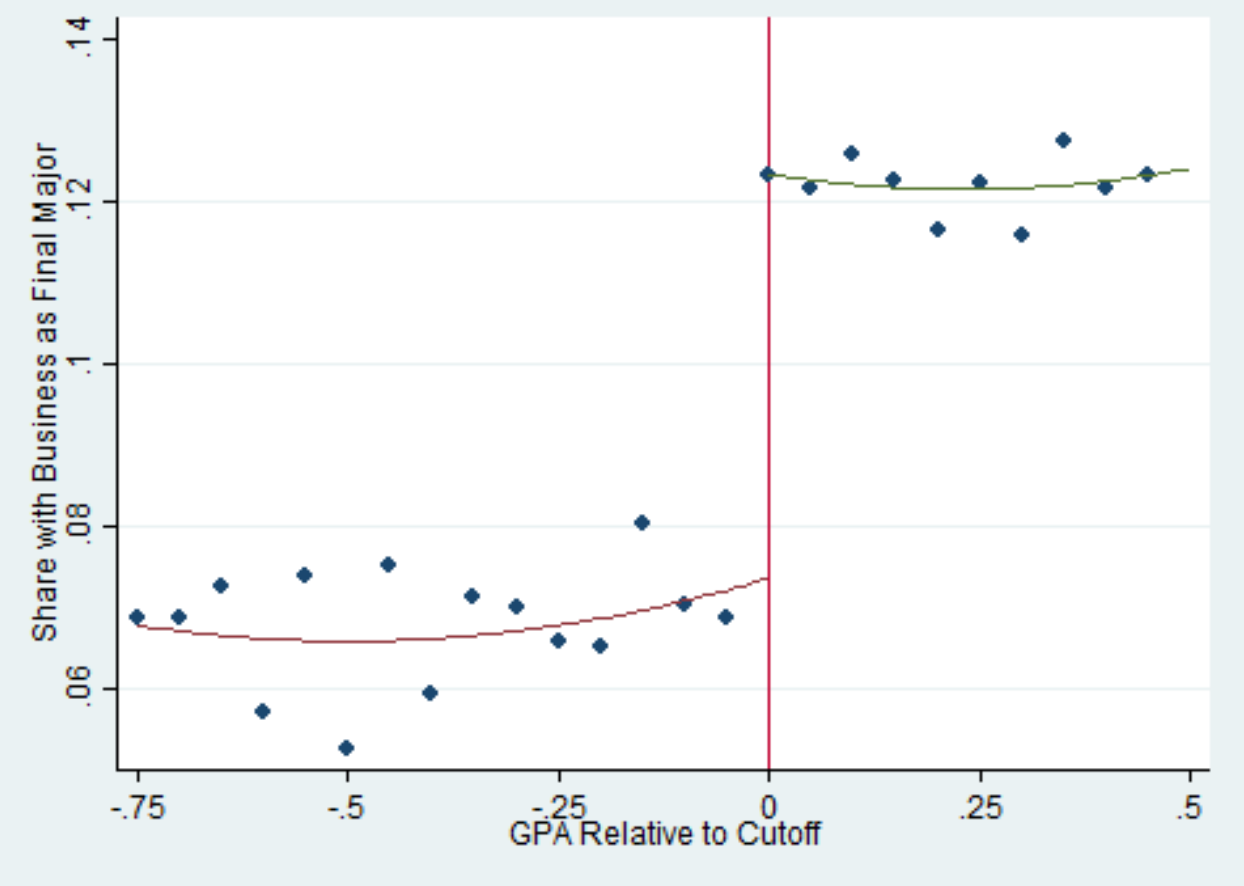

Max GPA is calculated as the maximum cumulative GPA during the $2^{\text {nd }}$ to $4^{\text {th }}$ semesters enrolled. The sample is restricted to Texas residents who enroll as a first-time four-year student in a cohort and institution identified as having a GPA cutoff and who do not select a business major in their $1^{\text {st }}$ semester. 
Figure 3: Six-Year Graduation Rate

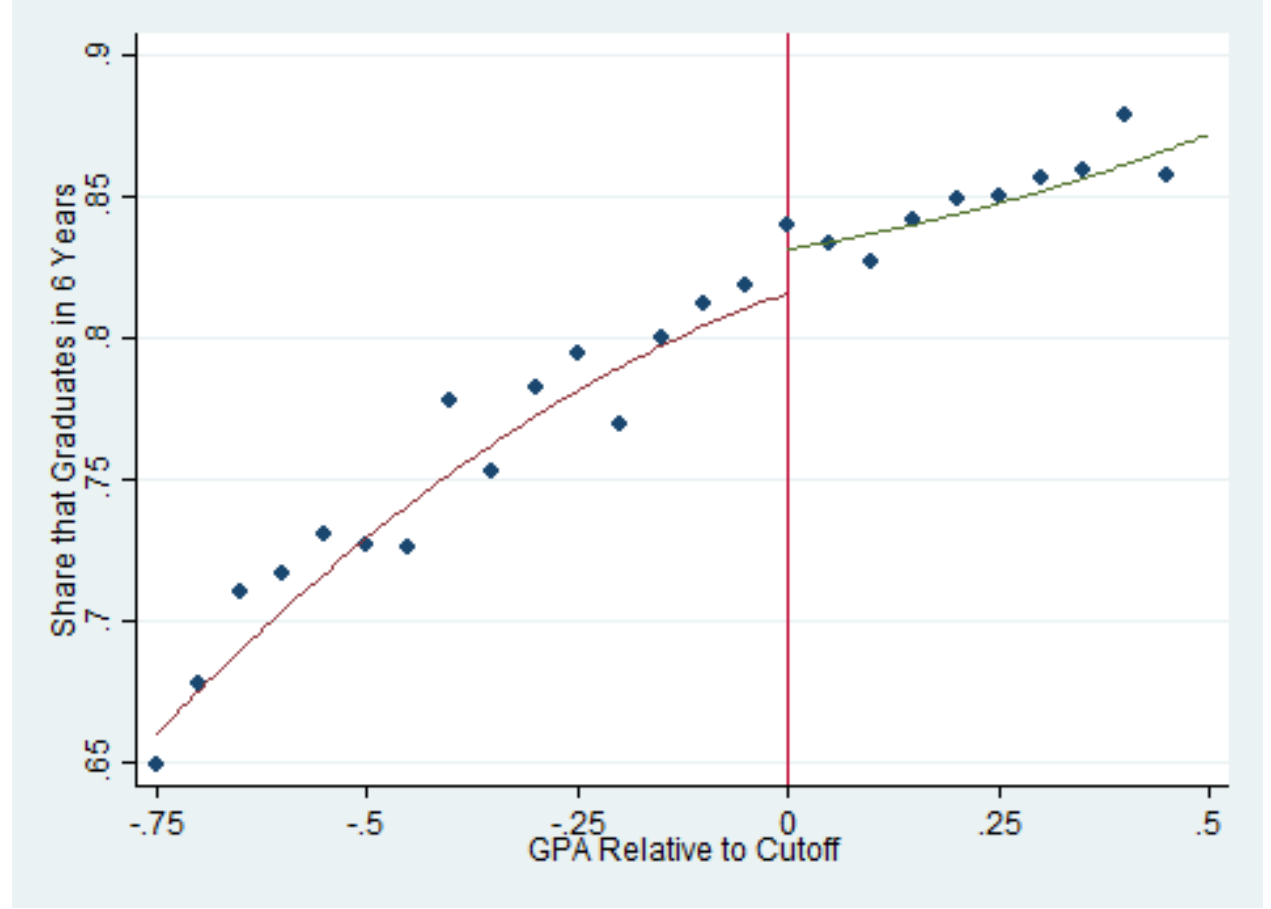

Max GPA is calculated as the maximum cumulative GPA during the $2^{\text {nd }}$ to $4^{\text {th }}$ semesters enrolled. The sample is restricted to Texas residents who enroll as a first-time four-year student in a cohort and institution identified as having a GPA cutoff and who do not select a business major in their $1^{\text {st }}$ semester. 
Figure 4: Effect of Exceeding Business GPA Cutoff on Earnings

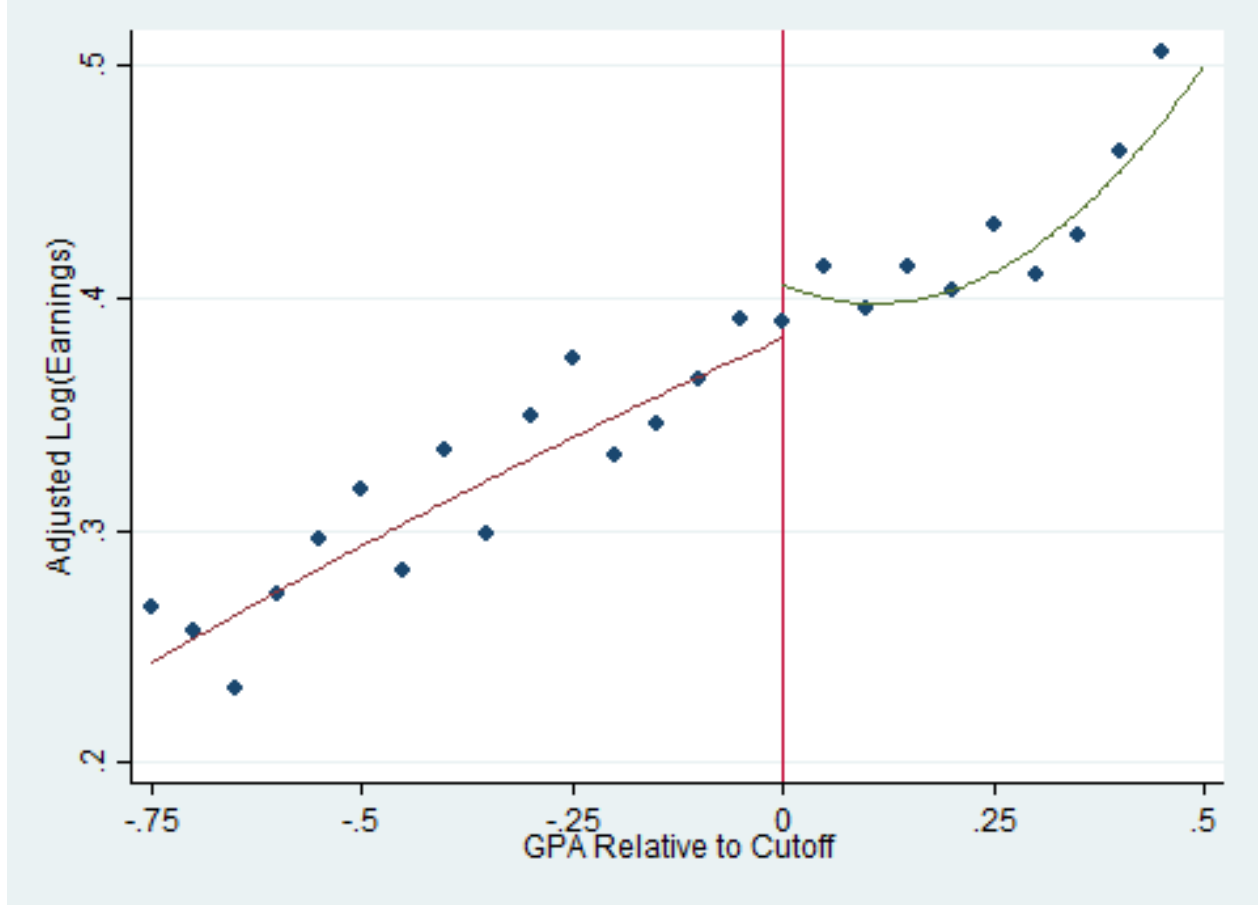

(a) Adjusted Ln(Earnings) 10 or More Years After College Entry

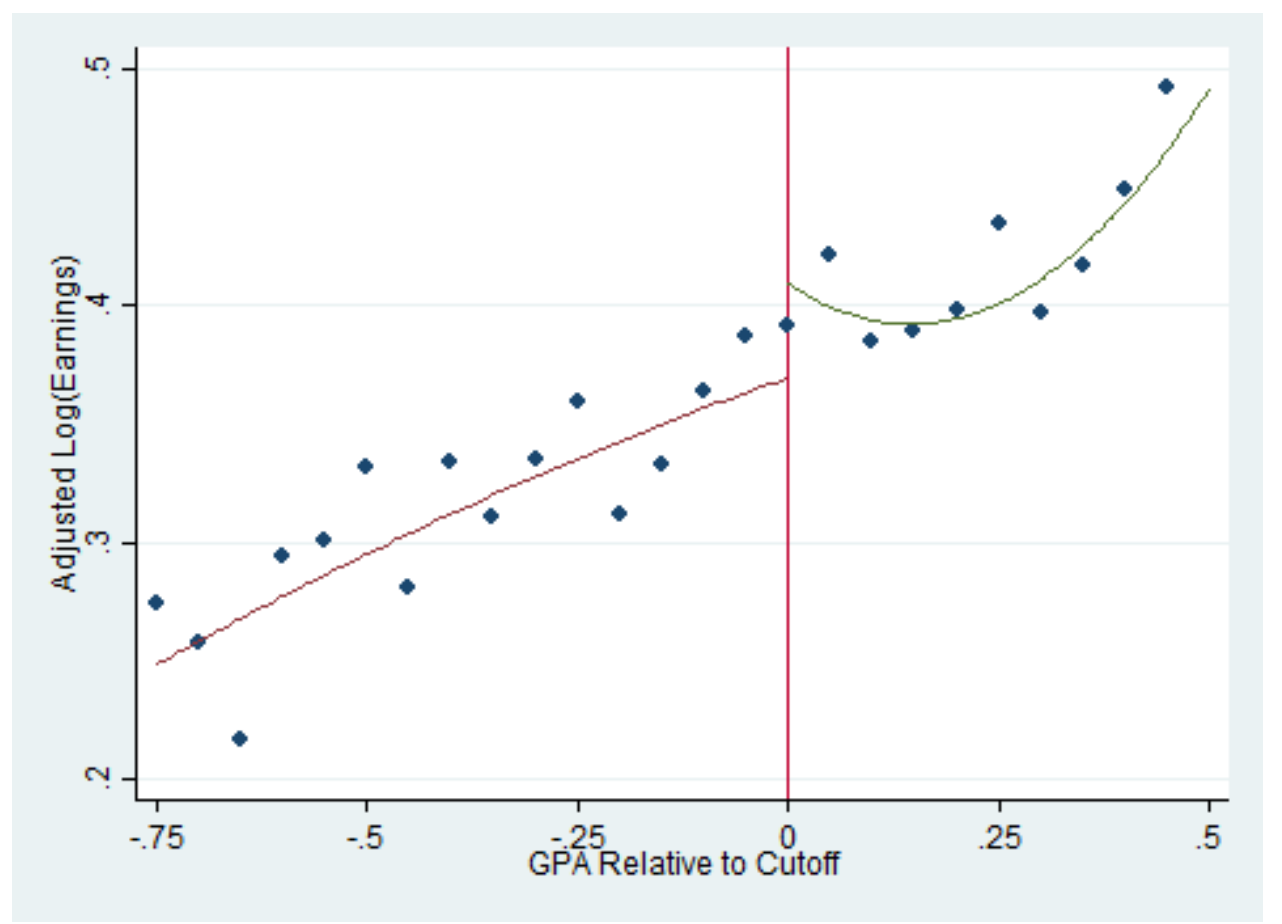

(b) Adjusted Ln(Earnings) 12 or More Years After College Entry

GPA is calculated as the maximum cumulative GPA during the $2^{\text {nd }}$ to $4^{\text {th }}$ semesters enrolled. The sample is restricted to Texas residents who enroll as a first-time four-year student in a cohort and institution identified as having a GPA cutoff and who do not select a business major in their $1^{\text {st }}$ semester. 


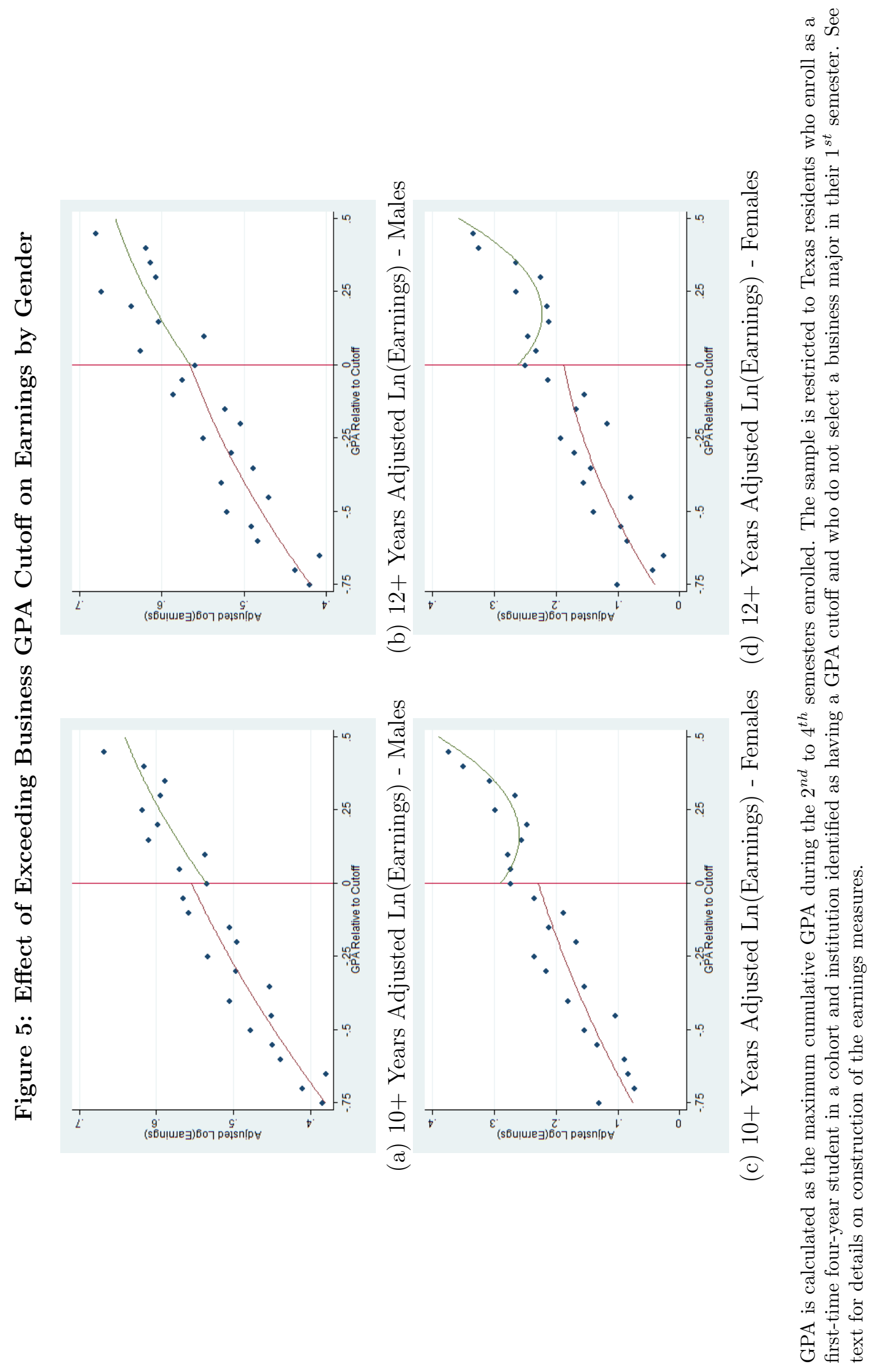




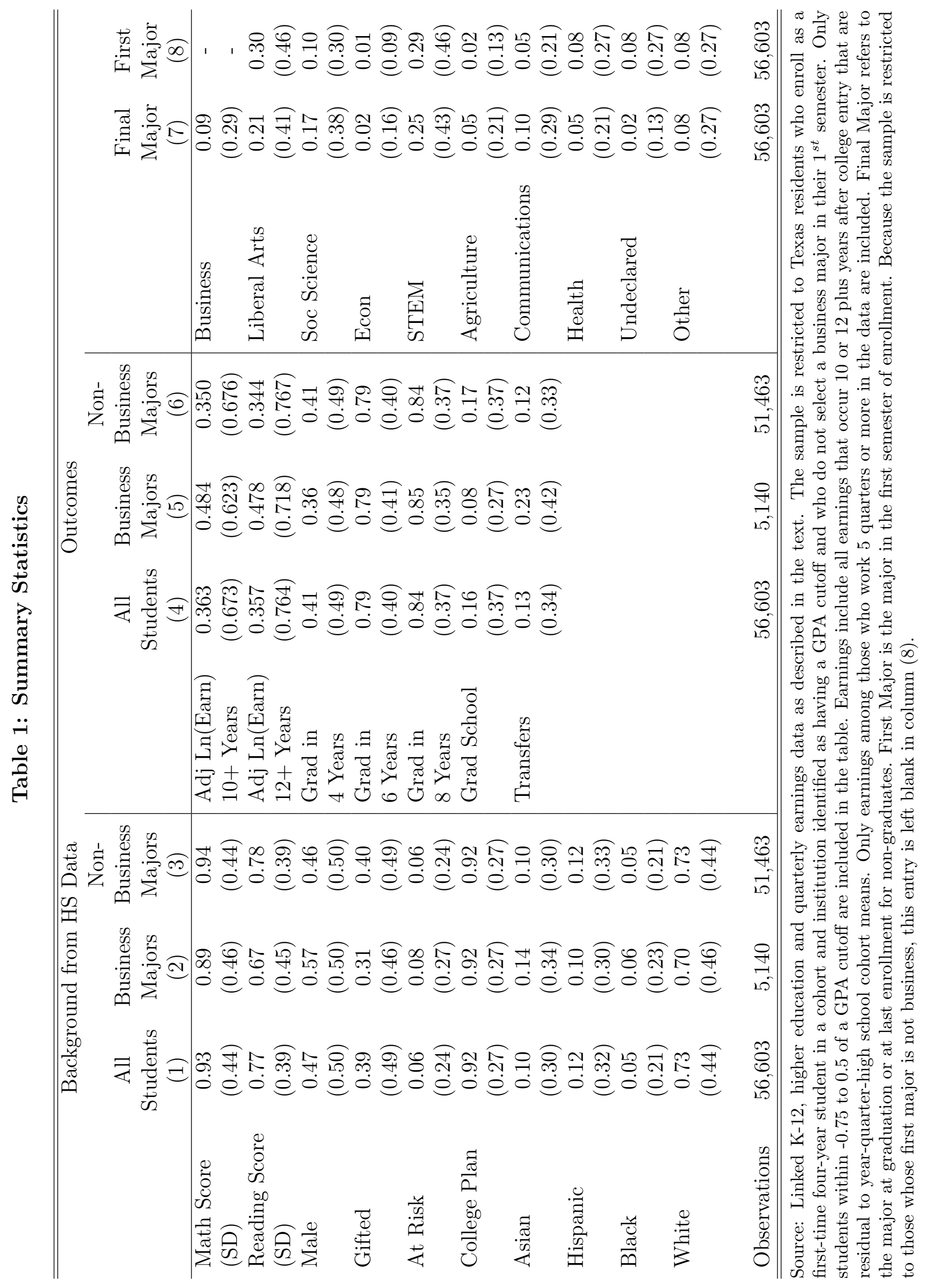




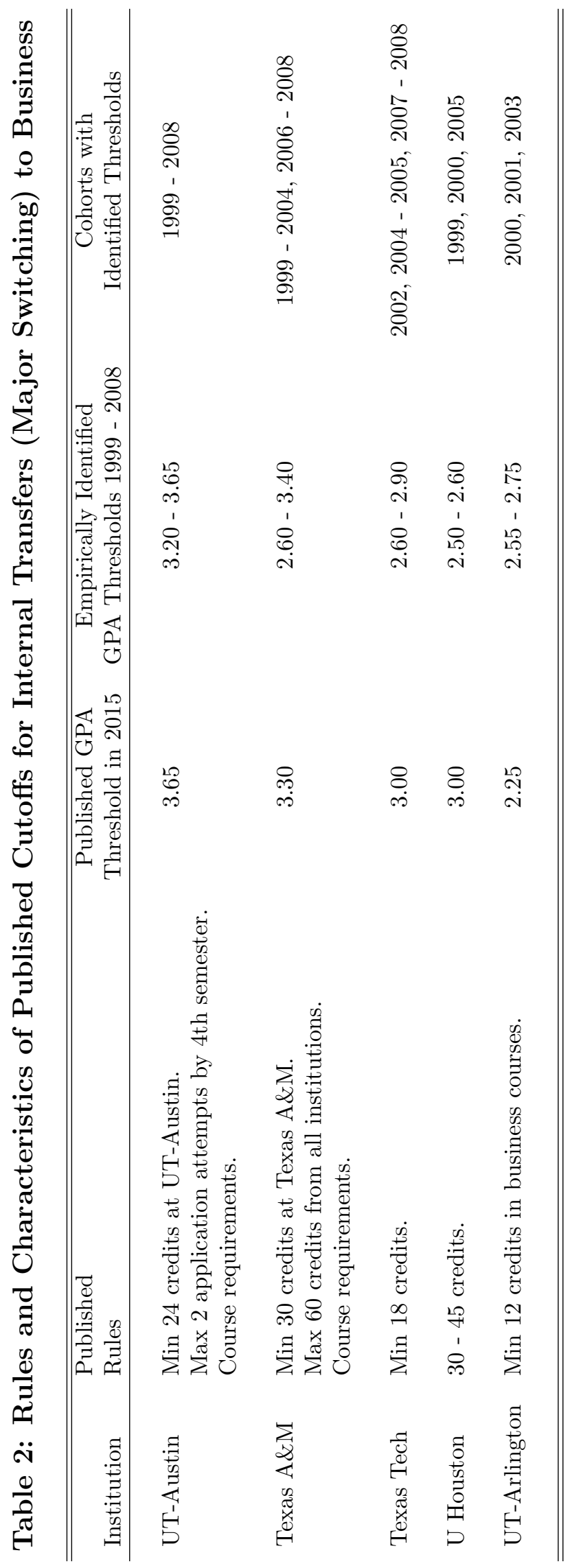


Table 3: Empirically Identified GPA Cutoffs by Cohort and Institution

\begin{tabular}{lcccc}
\hline \hline Institution & Entry Cohort & GPA & Estimate & t-statistic \\
\hline \multirow{3}{*}{ UT-Austin } & 1999 & 3.45 & 0.065 & 4.4 \\
& 2000 & 3.40 & 0.041 & 3.1 \\
& 2001 & 3.35 & 0.055 & 5.0 \\
& 2002 & 3.55 & 0.060 & 4.4 \\
& 2003 & 3.40 & 0.061 & 6.1 \\
& 2004 & 3.20 & 0.045 & 4.5 \\
& 2005 & 3.35 & 0.061 & 5.2 \\
& 2006 & 3.40 & 0.063 & 5.6 \\
Texas A\& M & 2007 & 3.65 & 0.086 & 5.3 \\
& 2008 & 3.50 & 0.050 & 4.1 \\
& & & & \\
& 1999 & 2.60 & 0.083 & 4.1 \\
& 2000 & 3.30 & 0.103 & 5.4 \\
& 2001 & 3.15 & 0.049 & 2.9 \\
& 2002 & 3.30 & 0.063 & 3.3 \\
& 2003 & 3.40 & 0.052 & 2.9 \\
UT-Arlington & 2004 & 3.05 & 0.037 & 2.6 \\
& 2006 & 3.00 & 0.048 & 3.3 \\
& 2007 & 3.10 & 0.052 & 3.6 \\
& 2008 & 2.70 & 0.061 & 4.2 \\
& & & & \\
& 2001 & 2.75 & 0.099 & 2.7 \\
& 2003 & 2.70 & 0.102 & 3.5 \\
& 2.55 & 0.086 & 3.1 \\
\hline \hline
\end{tabular}

GPA is calculated as the student's maximum cumulative GPA between the $2^{\text {nd }}$ and $4^{\text {th }}$ semesters enrolled, not including summer semesters. The GPA is also re-centered to be relative to the cutoff in each institution-cohort. Samples are restricted to students whose first observed enrollment is in a four-year institution and who are not declared for business in their first semester of enrollment and have a cumulative GPA of at least 2.0. For each institution-cohort, we estimate a separate regression of having a final major in business on a linear spline in maximum GPA between semesters 2 and 4 and a cutoff indicator progressively increased by 0.05 grade points from 2.5 to 3.8 . The GPA value that provides the cutoff estimate with the largest t-statistic for that institution-cohort is shown here provided the t-statistic exceeds 2.50 . 


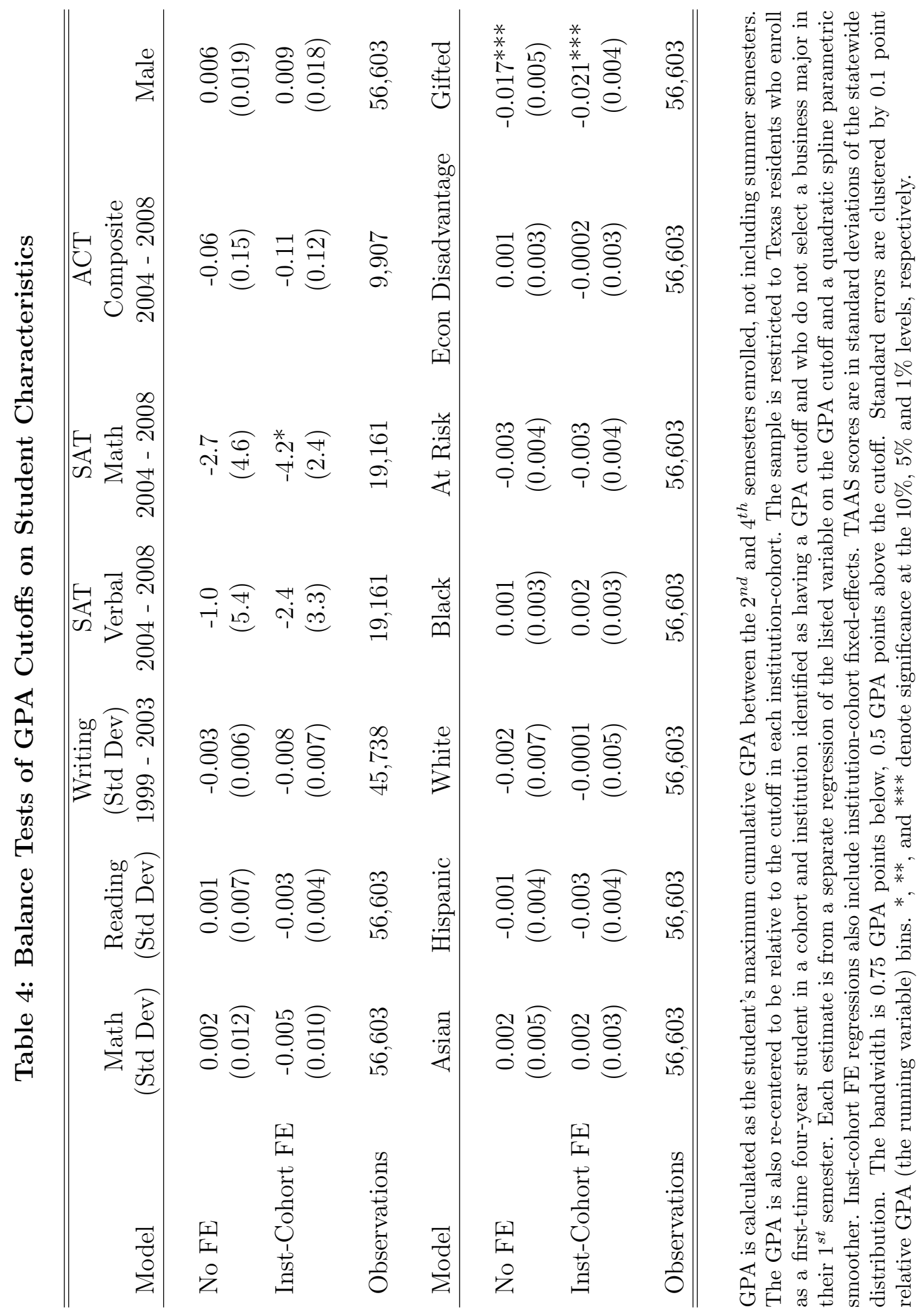


Table 5: Effect of Exceeding GPA Cutoff on Having a Final Major in Business

\begin{tabular}{|c|c|c|c|}
\hline Bandwidth & $\begin{array}{c}\text { No Controls } \\
(1)\end{array}$ & $\begin{array}{c}\text { Inst-Cohort FE } \\
(2)\end{array}$ & $\begin{array}{c}\text { Controls \& } \\
\text { Inst-Cohort FE } \\
(3)\end{array}$ \\
\hline$(-0.5,0.5)$ & $\begin{array}{c}0.0520 * * * \\
(0.0042)\end{array}$ & $\begin{array}{c}0.0533^{* * *} \\
(0.0037)\end{array}$ & $\begin{array}{c}0.0522^{* * *} \\
(0.0041)\end{array}$ \\
\hline Obs & 47,272 & 47,272 & 47,272 \\
\hline$(-0.75,0.5)$ & $\begin{array}{c}0.0486^{* * *} \\
(0.0052)\end{array}$ & $\begin{array}{c}0.0495^{* * *} \\
(0.0047)\end{array}$ & $\begin{array}{c}0.0488^{* * *} \\
(0.0050)\end{array}$ \\
\hline Obs & 56,603 & 56,603 & 56,603 \\
\hline$(-1,0.5)$ & $\begin{array}{c}0.0498^{* * *} \\
(0.0045)\end{array}$ & $\begin{array}{c}0.0504^{* * *} \\
(0.0043)\end{array}$ & $\begin{array}{c}0.0495 * * * \\
(0.0047)\end{array}$ \\
\hline Obs & 63,965 & 63,965 & 63,965 \\
\hline
\end{tabular}

GPA is calculated as the student's maximum cumulative GPA between the $2^{\text {nd }}$ and $4^{\text {th }}$ semesters enrolled, not including summer semesters. The GPA is also re-centered to be relative to the cutoff in each institution-cohort. The sample is restricted to Texas residents who enroll as a first-time fouryear student in a cohort and institution identified as having a GPA cutoff and who do not select a business major in their $1^{\text {st }}$ semester. All models include a quadratic spline in GPA. Models with controls include information from high school records for $11^{\text {th }}$ grade math and reading test scores, gifted status, gender, race, at-risk status, economic disadvantage, and whether the student had a college plan. Standard errors are clustered by 0.1 point relative GPA (the running variable) bins. ${ }^{*},{ }^{* *}$, and ${ }^{* * *}$ denote significance at the $1 \%, 5 \%$ and $10 \%$ levels, respectively. 


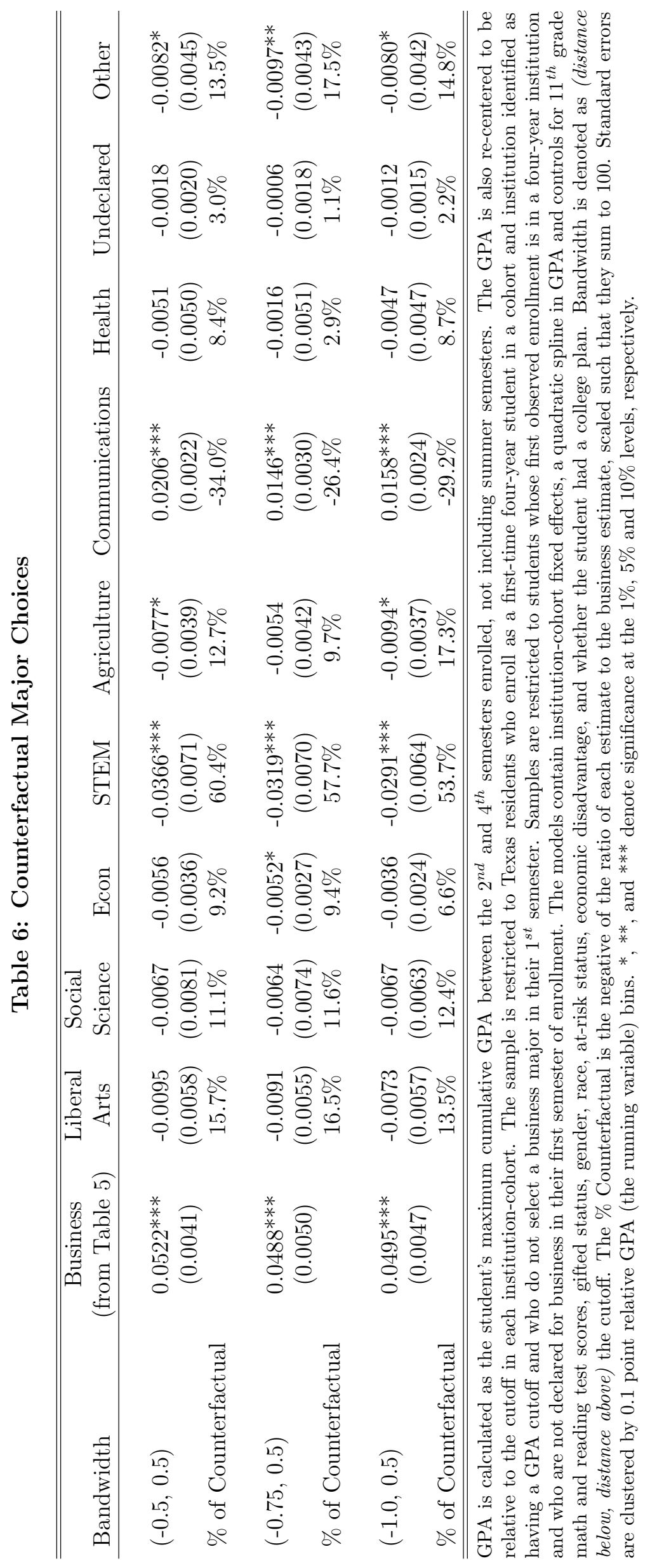


Table 7: IV Estimates of Majoring in Business on Education Outcomes

\begin{tabular}{|c|c|c|c|c|c|}
\hline Bandwidth & $\begin{array}{c}\text { Grad in } \\
4 \text { Years } \\
(1)\end{array}$ & $\begin{array}{c}\text { Grad in } \\
6 \text { Year } \\
(2)\end{array}$ & $\begin{array}{c}\text { Grad in } \\
8 \text { Years } \\
(3)\end{array}$ & $\begin{array}{c}\text { Attend Public } \\
\text { Grad School } \\
(4)\end{array}$ & $\begin{array}{c}\text { Transfer } \\
(5)\end{array}$ \\
\hline & \multicolumn{5}{|c|}{ A. Bandwidth $=(-0.5,0.5)$} \\
\hline$(-0.5,0.5)$ & $\begin{array}{c}0.041 \\
(0.136)\end{array}$ & $\begin{array}{c}0.130 \\
(0.136)\end{array}$ & $\begin{array}{c}0.067 \\
(0.140)\end{array}$ & $\begin{array}{l}-0.090 \\
(0.176)\end{array}$ & $\begin{array}{r}-0.082 \\
(0.102)\end{array}$ \\
\hline Observations & 47,272 & 47,272 & 47,272 & 47,272 & 47,272 \\
\hline & \multicolumn{5}{|c|}{ B. Bandwidth $=(-0.75,0.5)$} \\
\hline$(-0.75,0.5)$ & $\begin{array}{c}0.008 \\
(0.157)\end{array}$ & $\begin{array}{c}0.181 \\
(0.155)\end{array}$ & $\begin{array}{c}0.121 \\
(0.157)\end{array}$ & $\begin{array}{c}0.016 \\
(0.194)\end{array}$ & $\begin{array}{r}-0.175 \\
(0.123)\end{array}$ \\
\hline Observations & 56,603 & 56,603 & 56,603 & 56,603 & 56,603 \\
\hline & \multicolumn{5}{|c|}{ C. Bandwidth $=(-1.0,0.5)$} \\
\hline$(-1.0,0.5)$ & $\begin{array}{c}0.010 \\
(0.157)\end{array}$ & $\begin{array}{c}0.202 \\
(0.155)\end{array}$ & $\begin{array}{c}0.148 \\
(0.154)\end{array}$ & $\begin{array}{l}-0.003 \\
(0.183)\end{array}$ & $\begin{array}{r}-0.178 \\
(0.113)\end{array}$ \\
\hline Observations & 63,965 & 63,965 & 63,965 & 63,965 & 63,965 \\
\hline
\end{tabular}

GPA is calculated as the student's maximum cumulative GPA between the $2^{\text {nd }}$ and $4^{\text {th }}$ semesters enrolled, not including summer semesters. The GPA is also re-centered to be relative to the cutoff in each institution-cohort. The sample is restricted to Texas residents who enroll as a first-time four-year student in a cohort and institution identified as having a GPA cutoff and who do not select a business major in their $1^{\text {st }}$ semester. All models include institution-cohort fixed-effects, a quadratic spline in GPA, $11^{\text {th }}$ grade math and reading test scores, gifted status, gender, race, at-risk status, economic disadvantage, and whether the student had a college plan. Bandwidth is denoted as (distance below, distance above) the cutoff. Standard errors are clustered by 0.1 point relative GPA (the running variable) bins. ${ }^{*}, * *$, and ${ }^{* * *}$ denote significance at the $1 \%, 5 \%$ and $10 \%$ levels, respectively. 


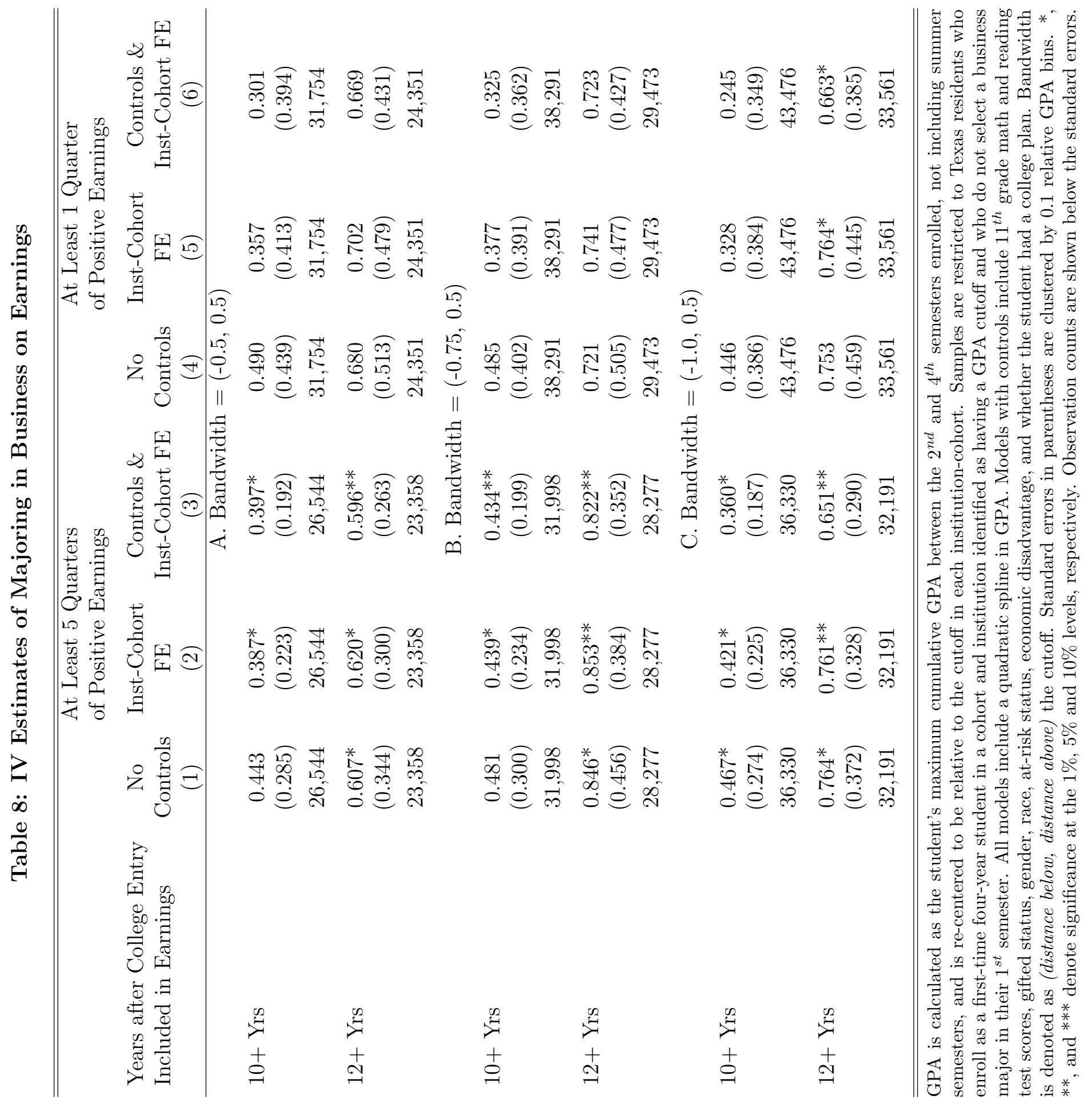




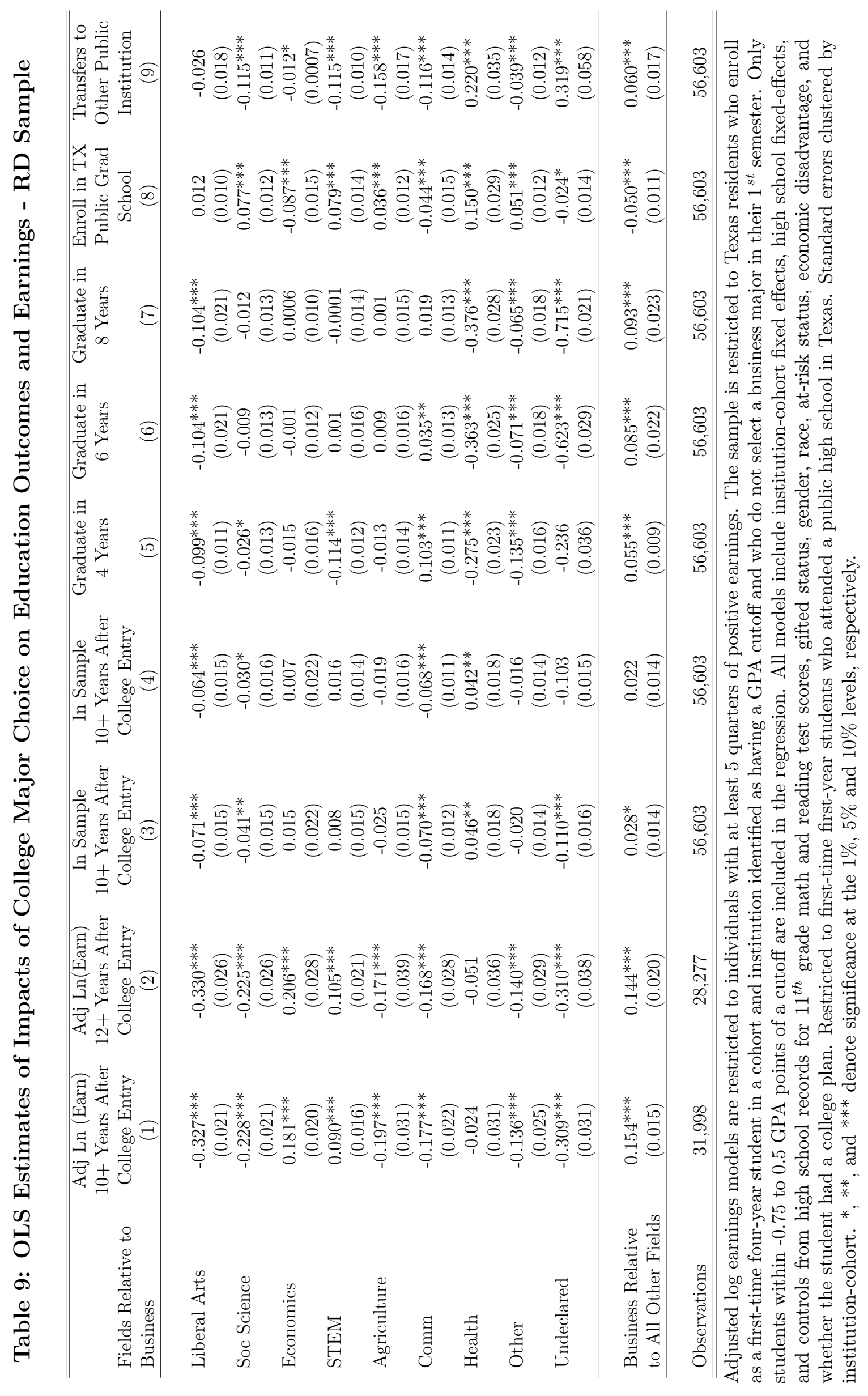




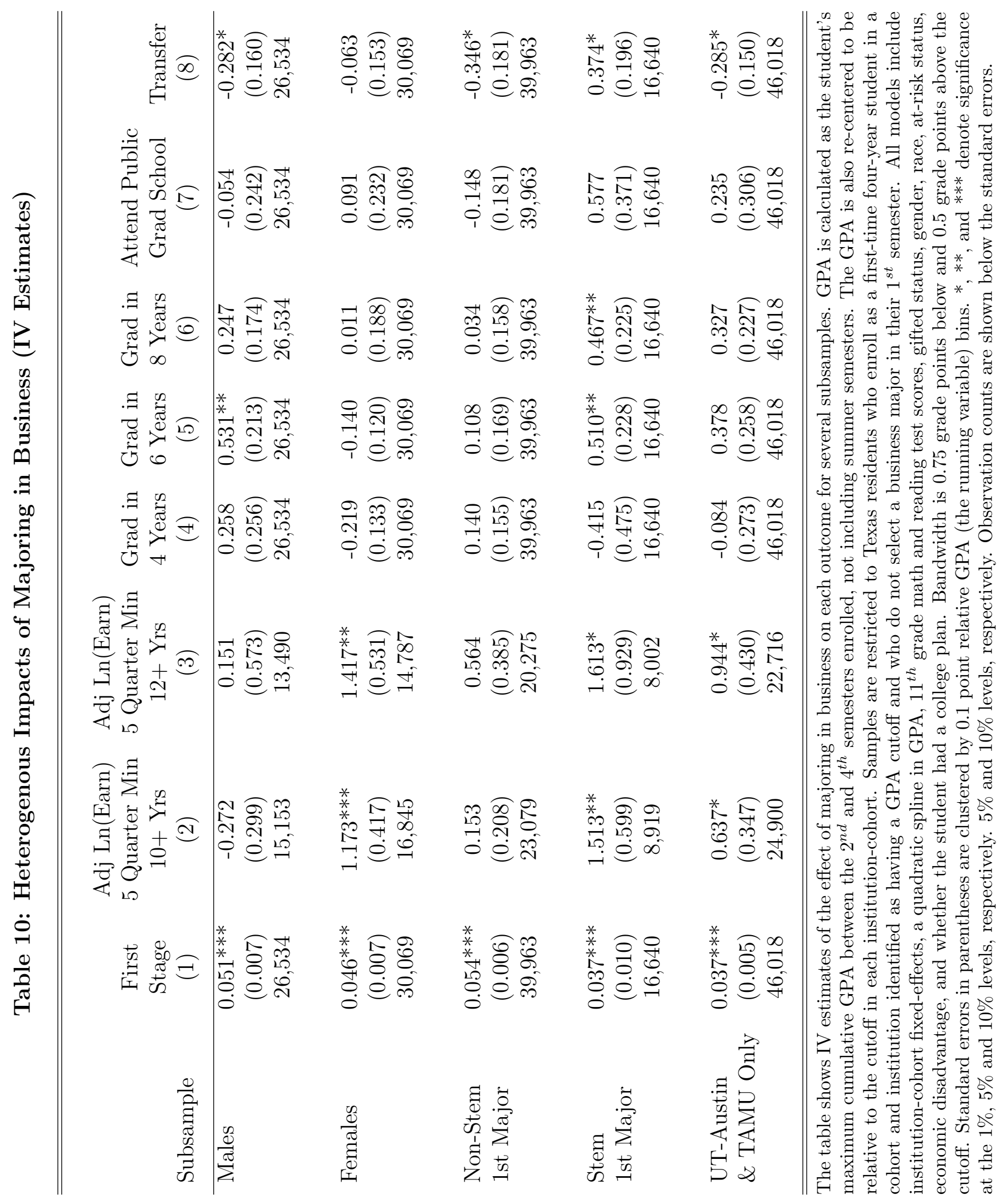


A Online Appendix 
Figure A-1: Discontinuity Density Test (McCray, 2008)

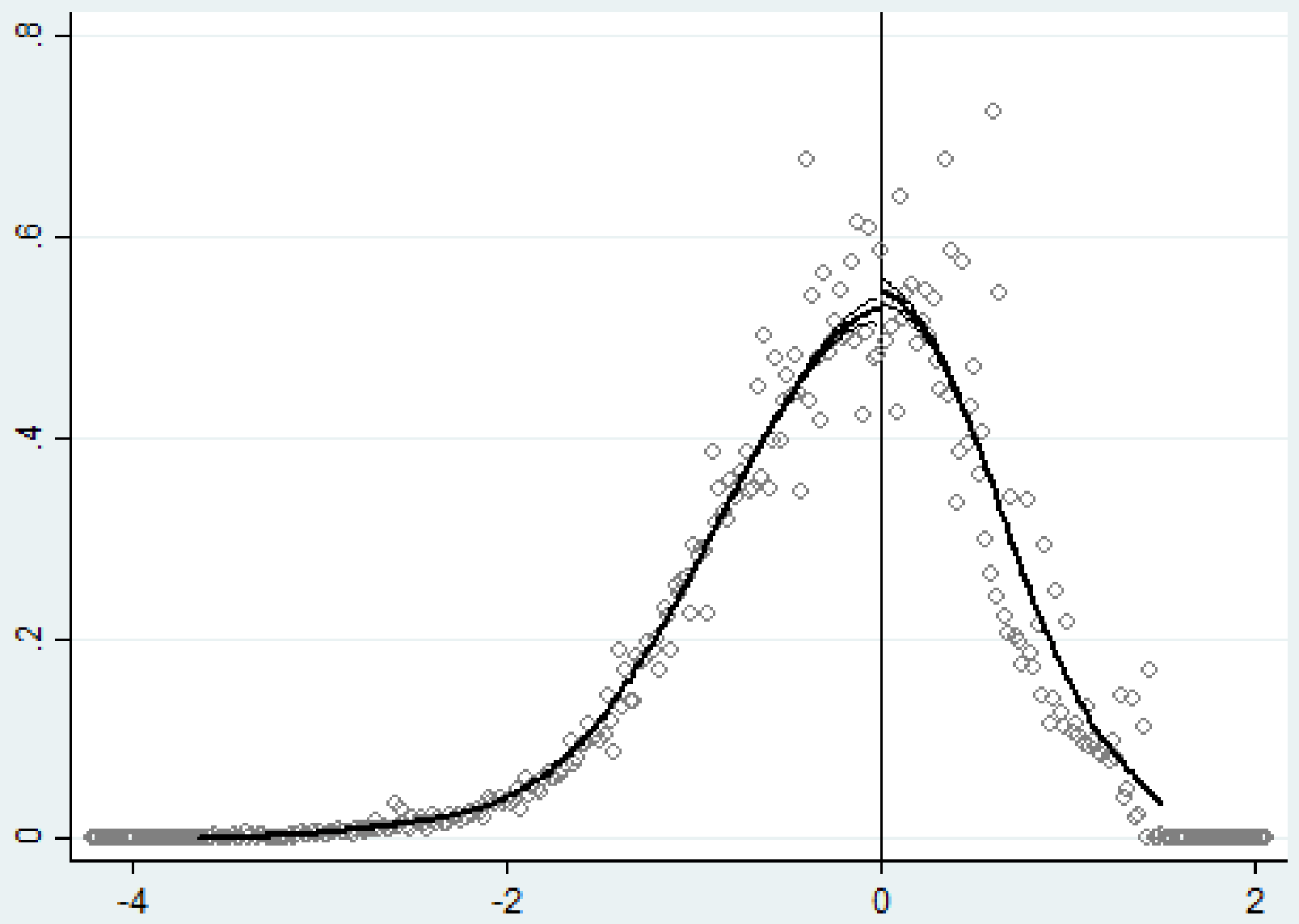

49 
Figure A-2: Other Final Majors as Functions of Max GPA

(a) Social Science

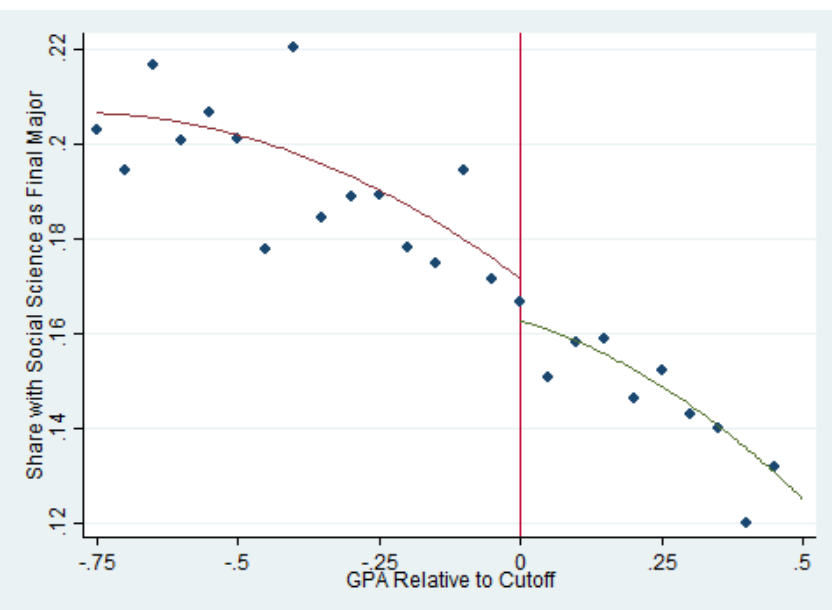

(b) Economics

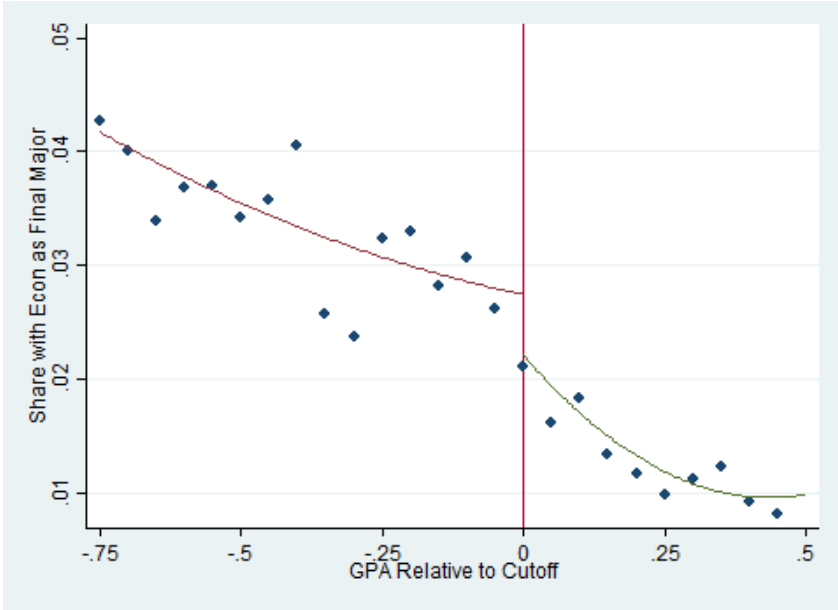

(c) Liberal Arts \& Humanities

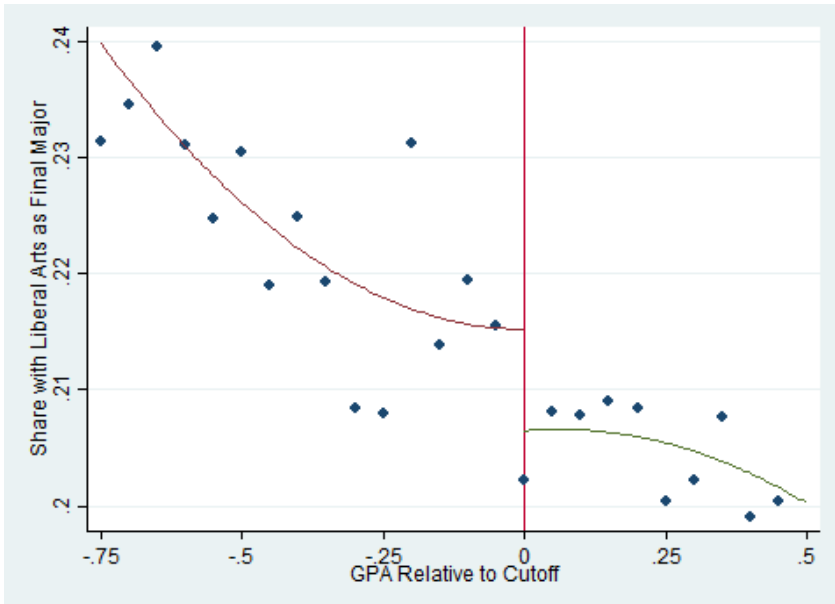


(d) Health

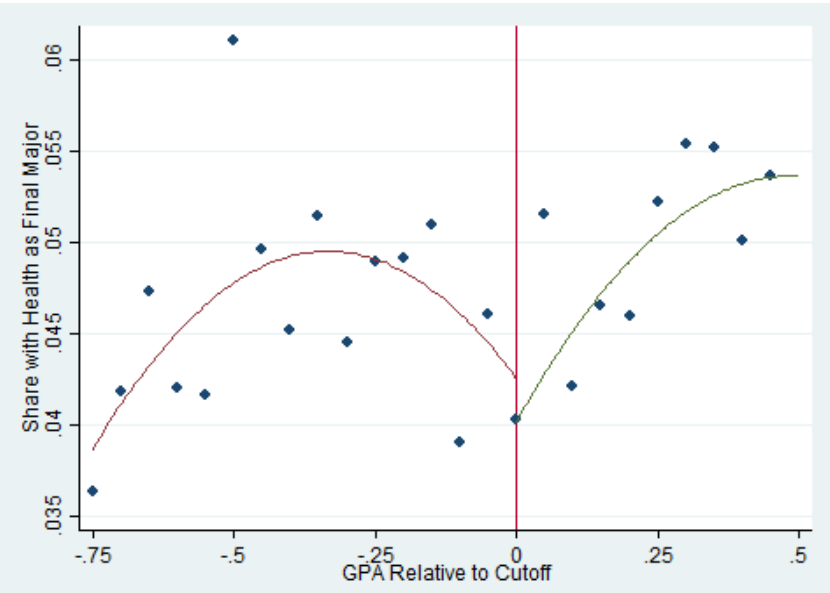

(e) Agriculture

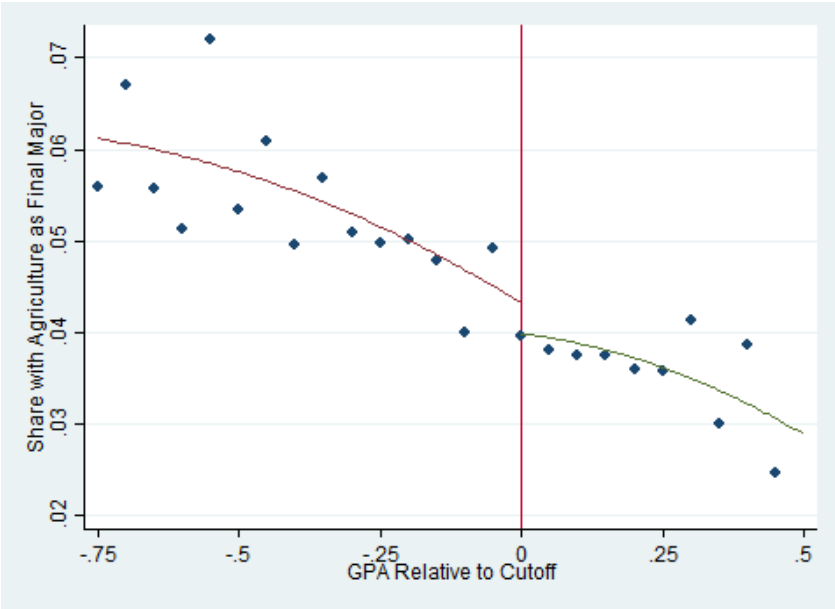

(f) Communications

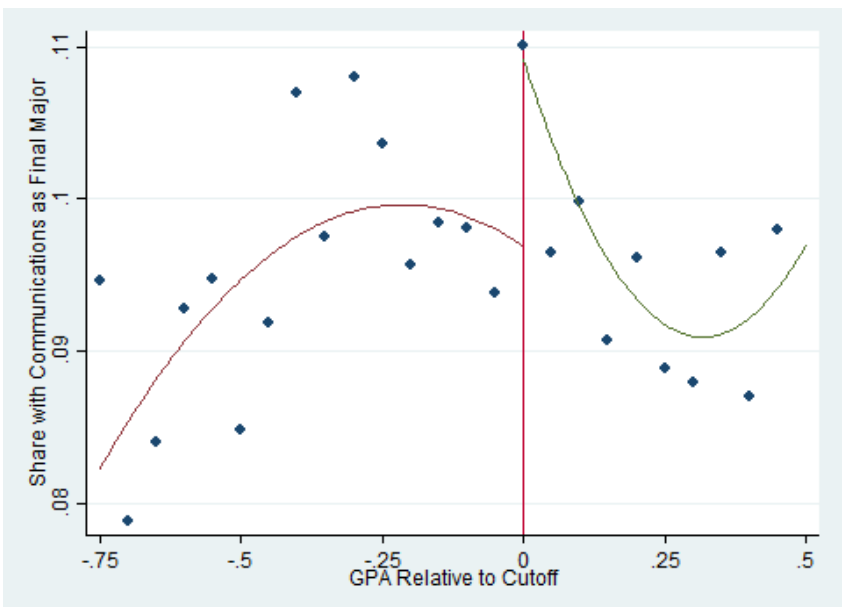


(d) Other Major

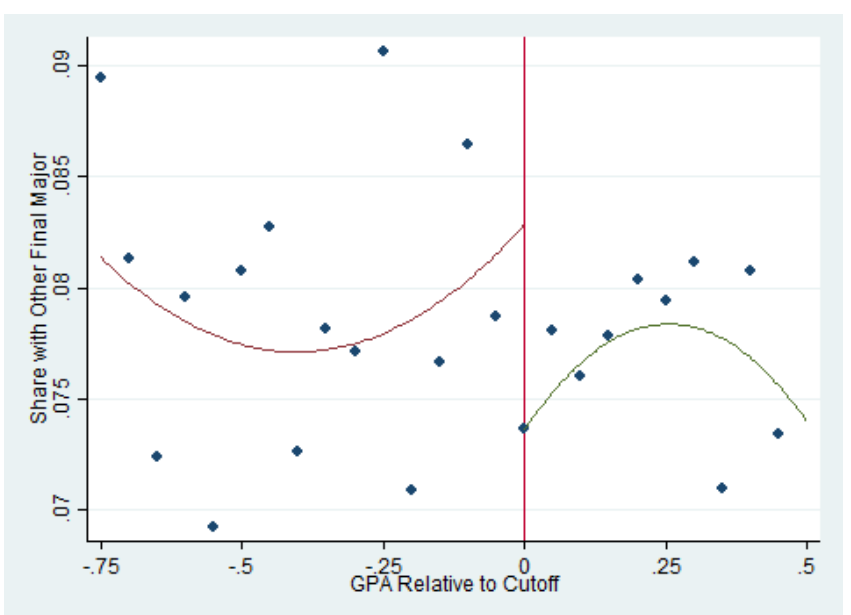

(e) Undeclared

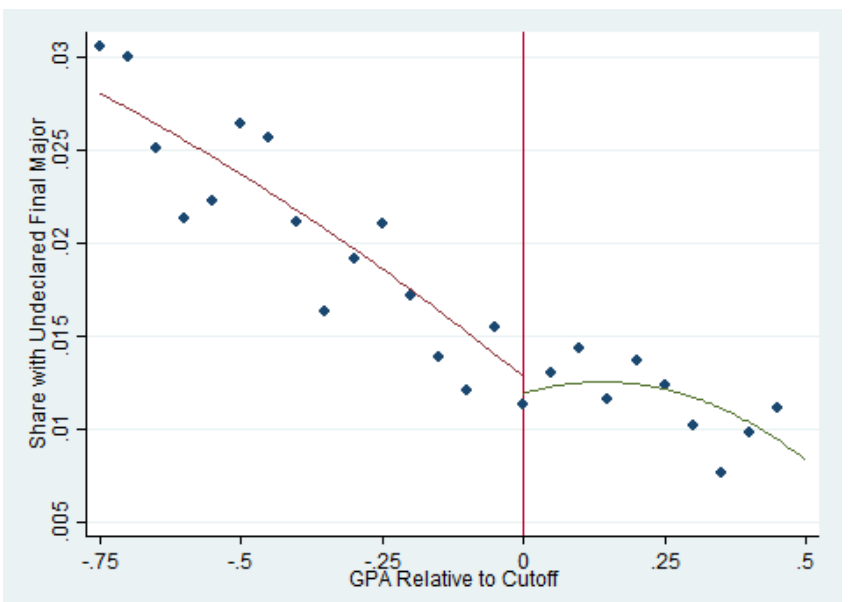

Max GPA calculated as the maximum cumulative GPA during the $2^{\text {nd }}$ to $4^{\text {th }}$ semesters enrolled. Sample is restricted to TX residents who enroll as a first-time four-year student and do not select a business major in their $1^{\text {st }}$ semester. 
Figure A-3: Additional Education Outcomes

(a) 4-Year Graduation

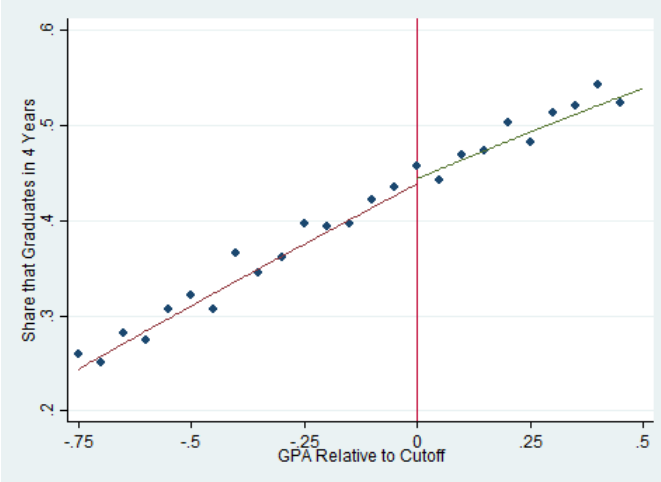

(b) 8-Year Graduation

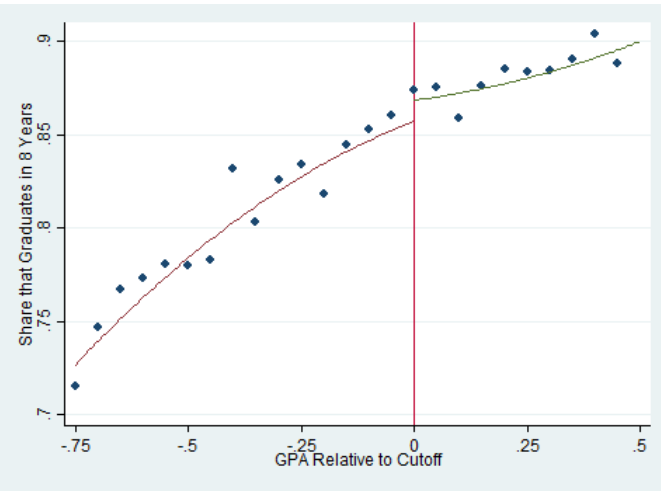

(c) Public Grad School Attendance

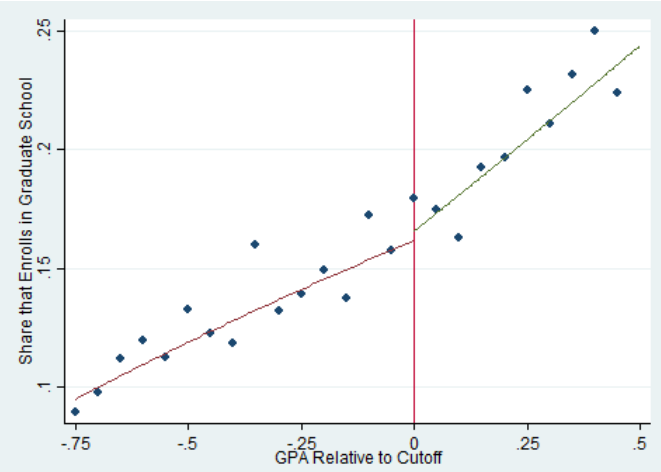

(d) Transferring

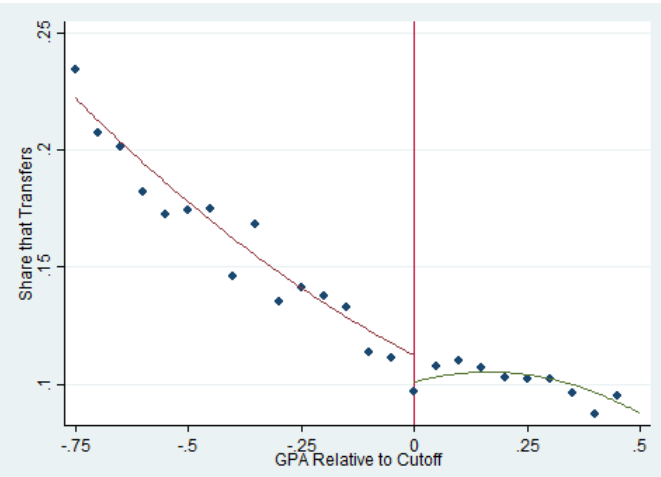

Max GPA calculated as the maximum cumulative GPA during the $2^{\text {nd }}$ to $4^{\text {th }}$ semesters enrolled. Sample is restricted to TX residents who enroll as a first-time four-year student and do not select a business major in their $1^{\text {st }}$ semester. 
Figure A-4: Institution-Year Business Major by GPA Plots - UT at Austin

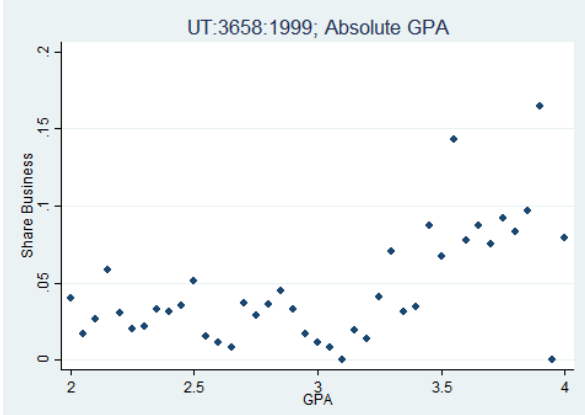

Cutoff $=3.45$

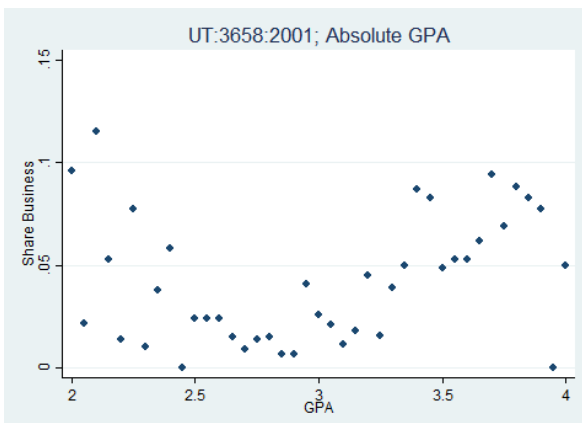

Cutoff $=3.35$

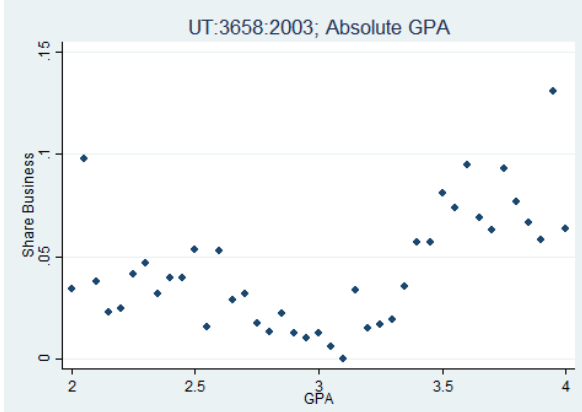

Cutoff $=3.40$

UT:3658:2005; Absolute GPA

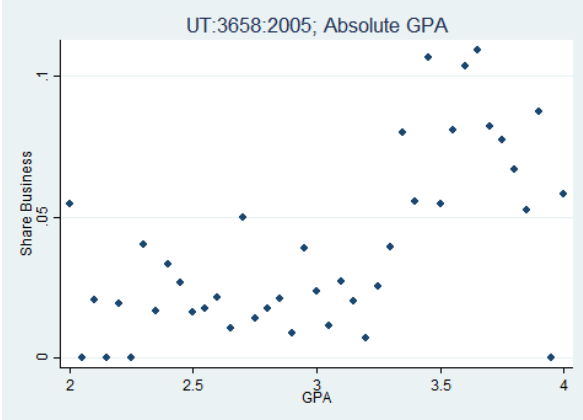

Cutoff $=3.35$

UT:3658:2007; Absolute GPA

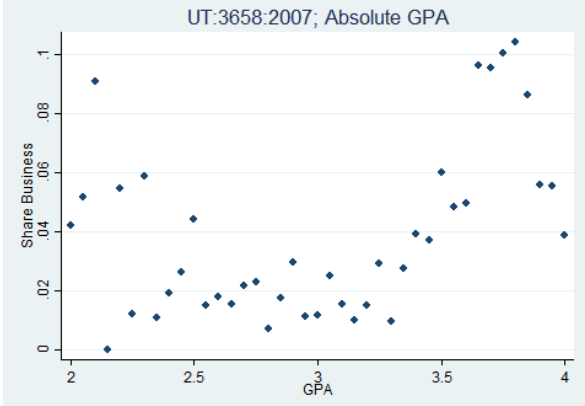

Cutoff $=3.65$

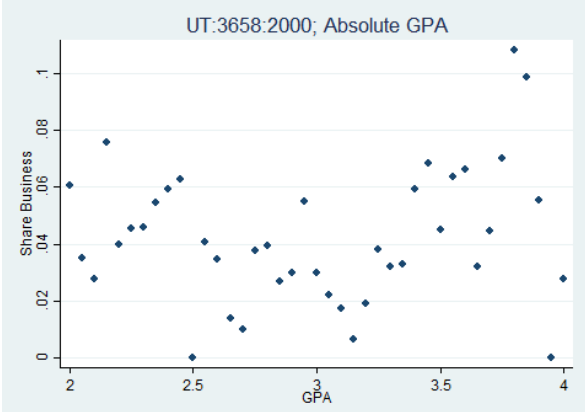

Cutoff $=3.40$

UT:3658:2002; Absolute GPA

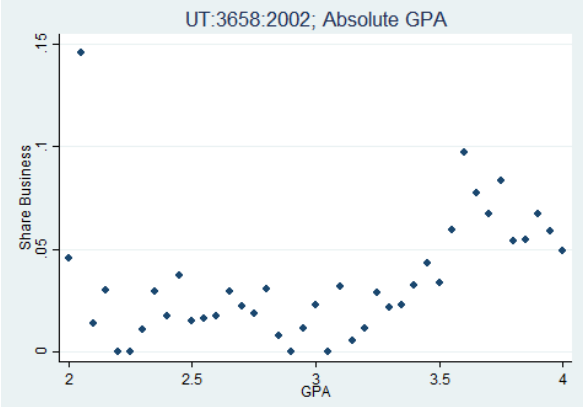

Cutoff $=3.55$

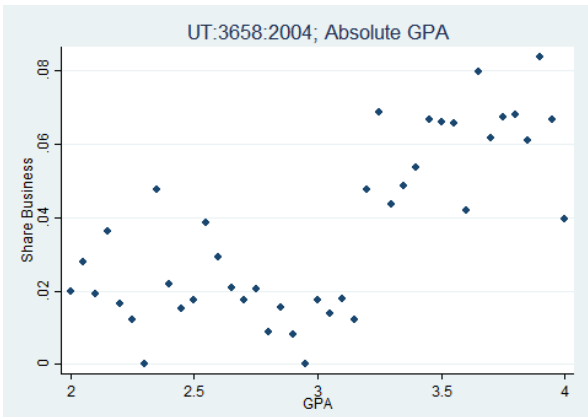

Cutoff $=3.20$

UT:3658:2006; Absolute GPA

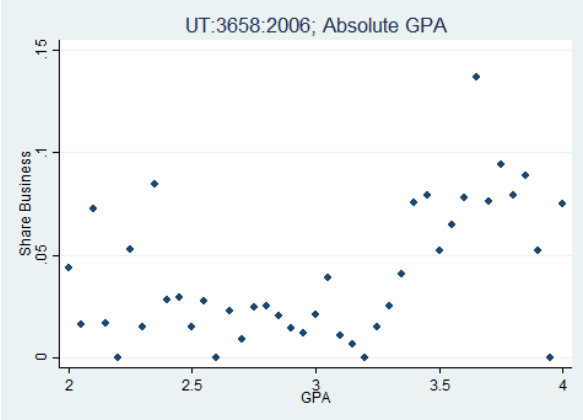

Cutoff $=3.40$

UT:3658:2008; Absolute GPA

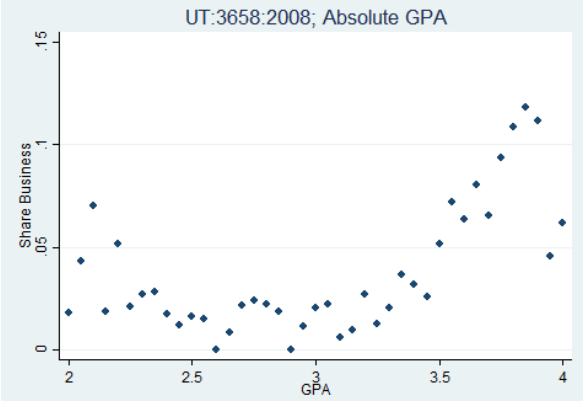

Cutoff $=3.50$ 
Figure A-5: Institution-Year Business Major by GPA Plots - Texas A\&M

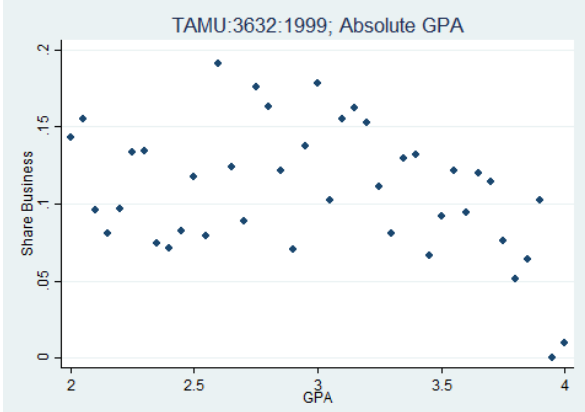

Cutoff $=2.60$

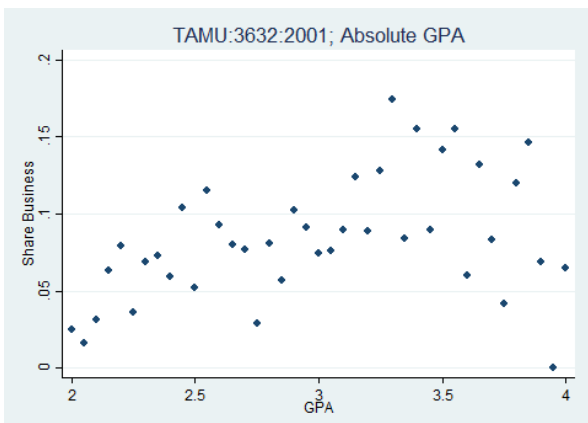

Cutoff $=3.15$

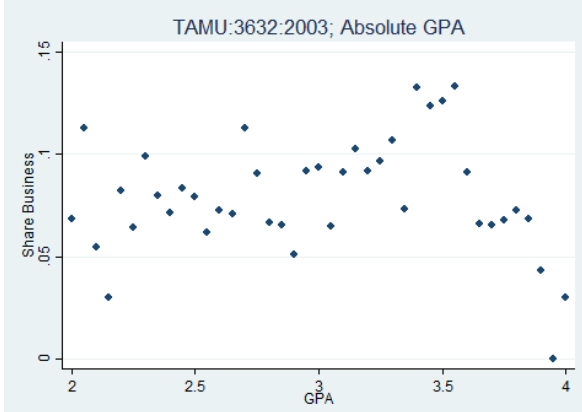

Cutoff $=3.40$

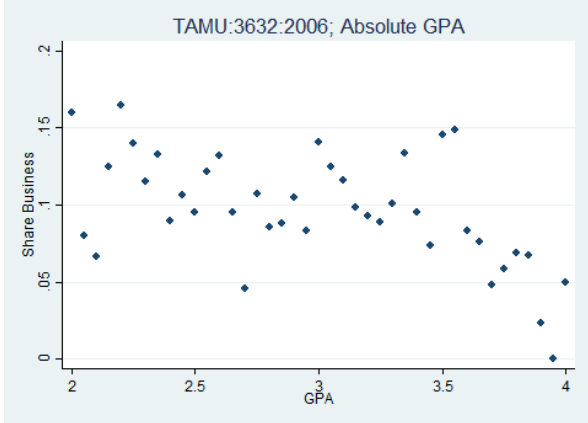

Cutoff $=3.30$

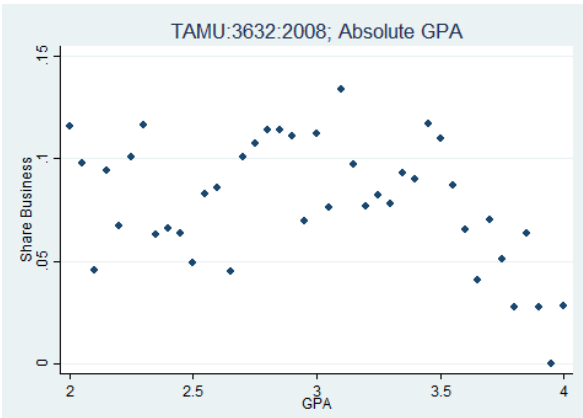

Cutoff $=2.70$

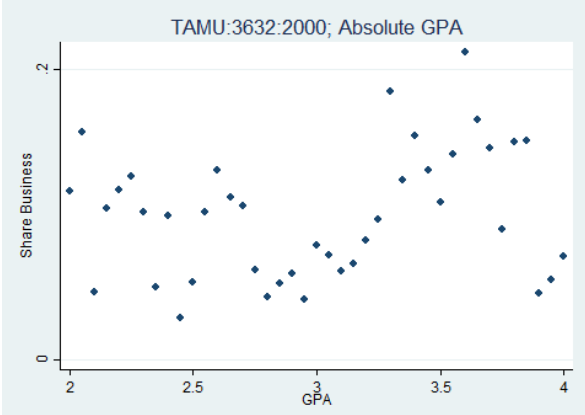

Cutoff $=3.30$

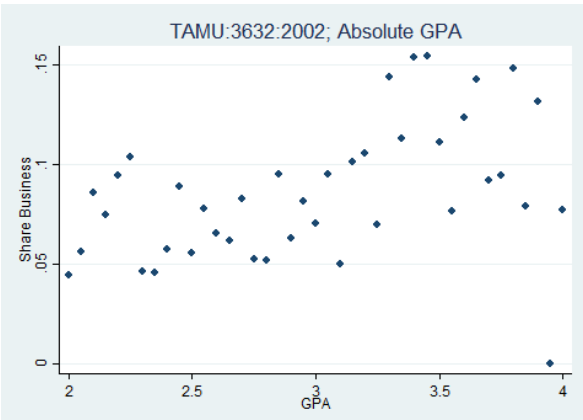

Cutoff $=3.30$

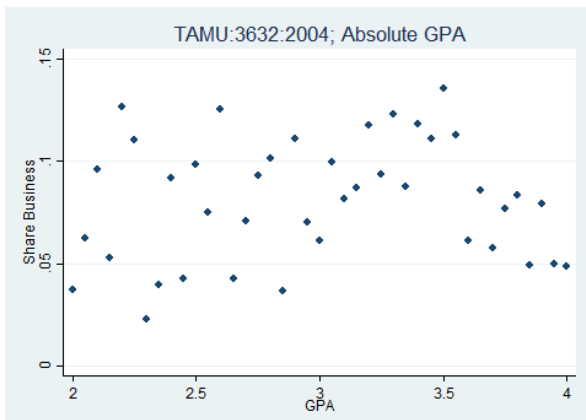

Cutoff $=3.05$

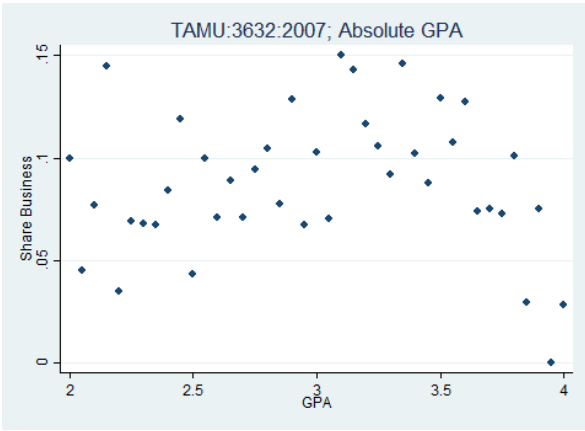

Cutoff $=3.30$ 
Figure A-6: Institution-Year Business Major by GPA Plots - Texas Tech
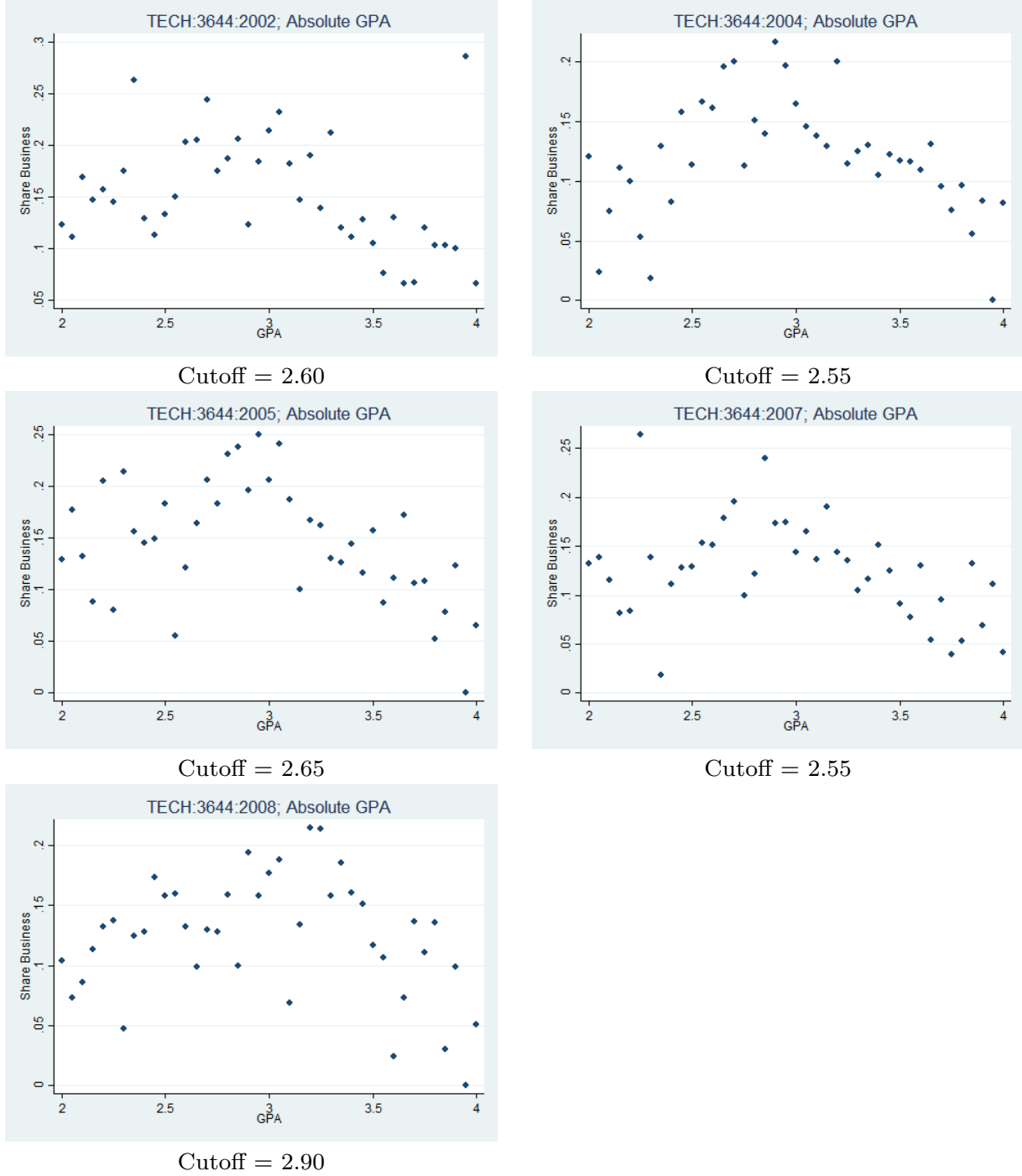
Figure A-7: Institution-Year Business Major by GPA Plots - University of Houston
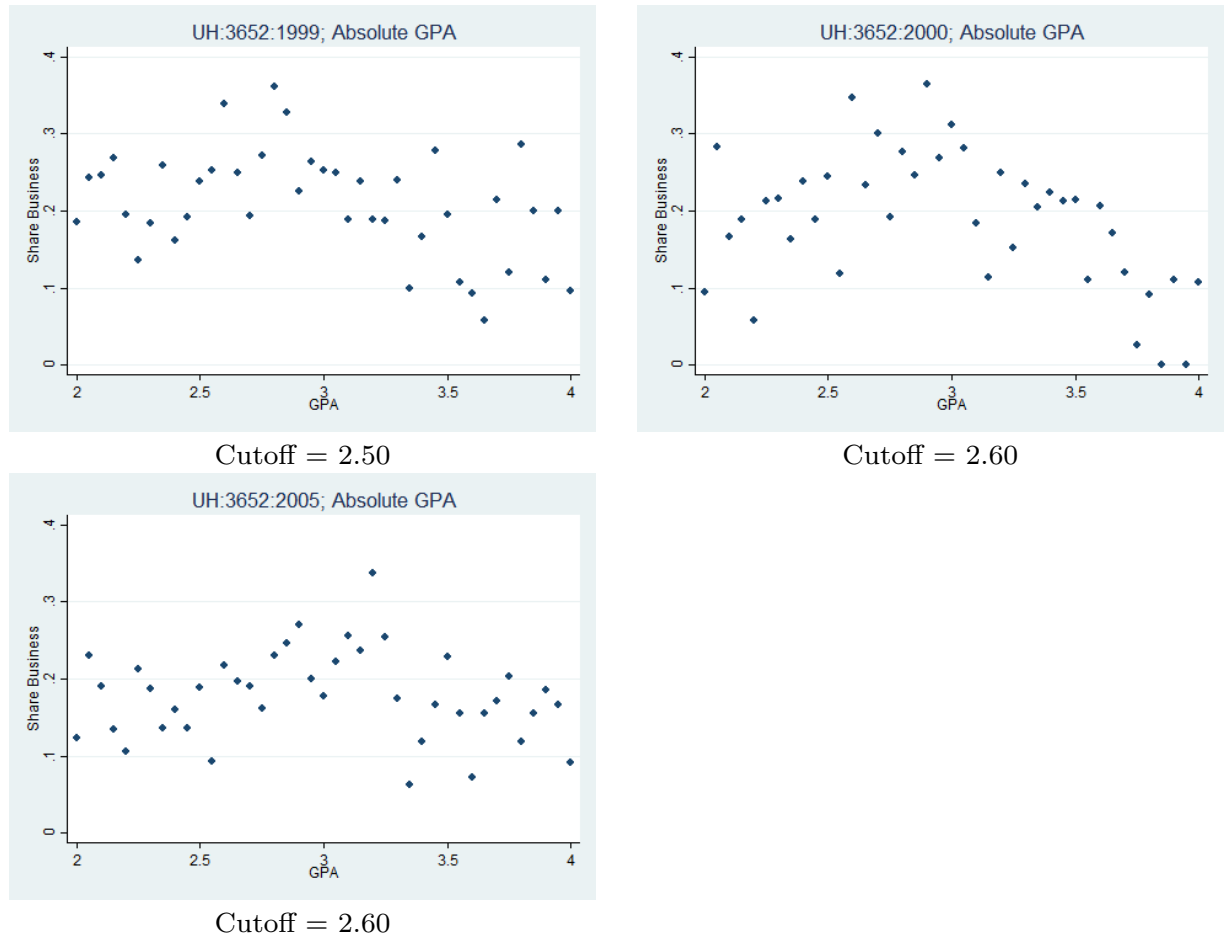

Figure A-8: Institution-Year Business Major by GPA Plots - UT at Arlington
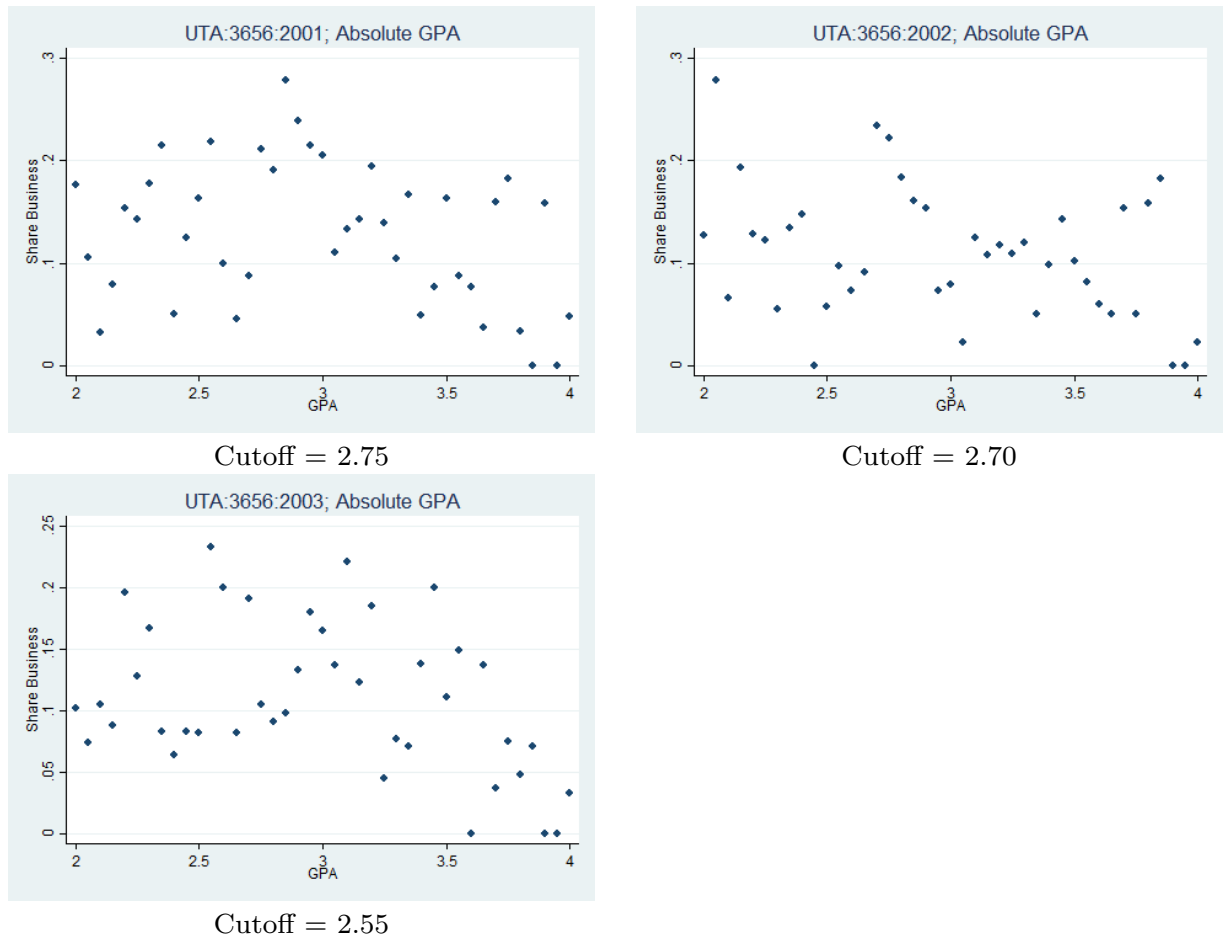
Figure A-9: T-Statistic For Cutoff by GPA, Institution, and Year
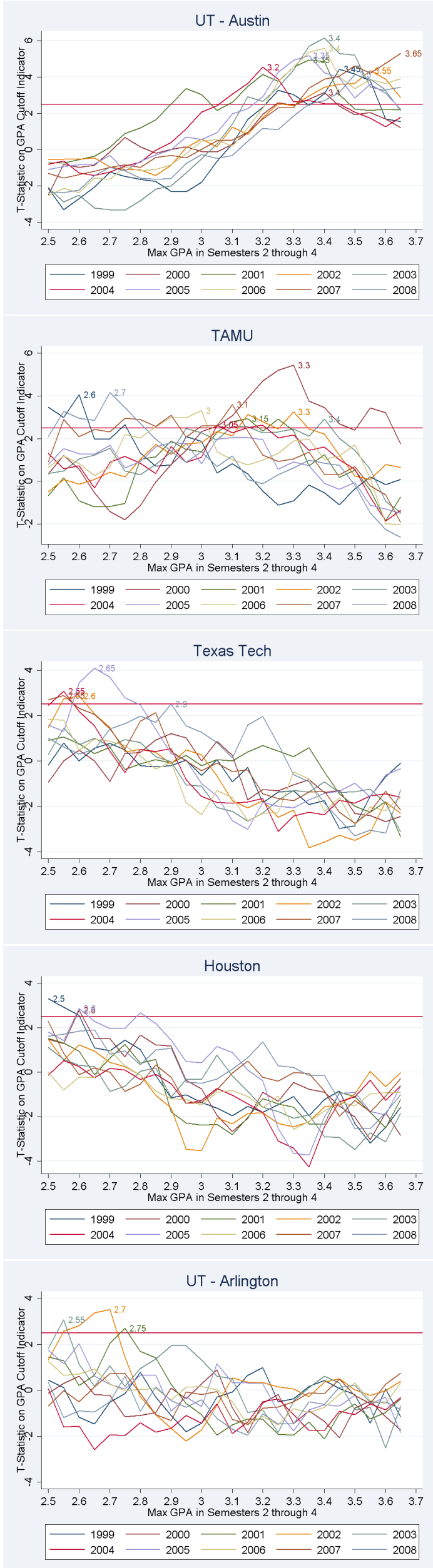


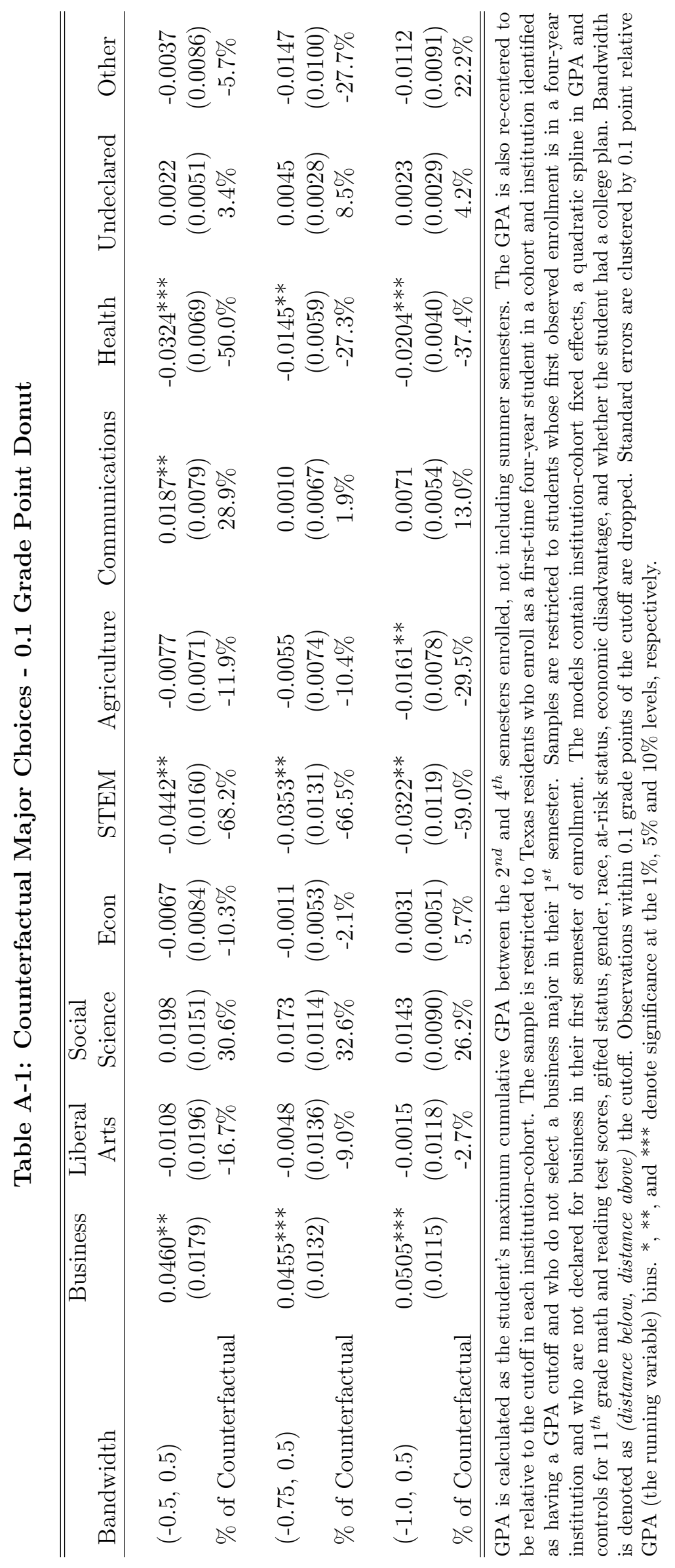




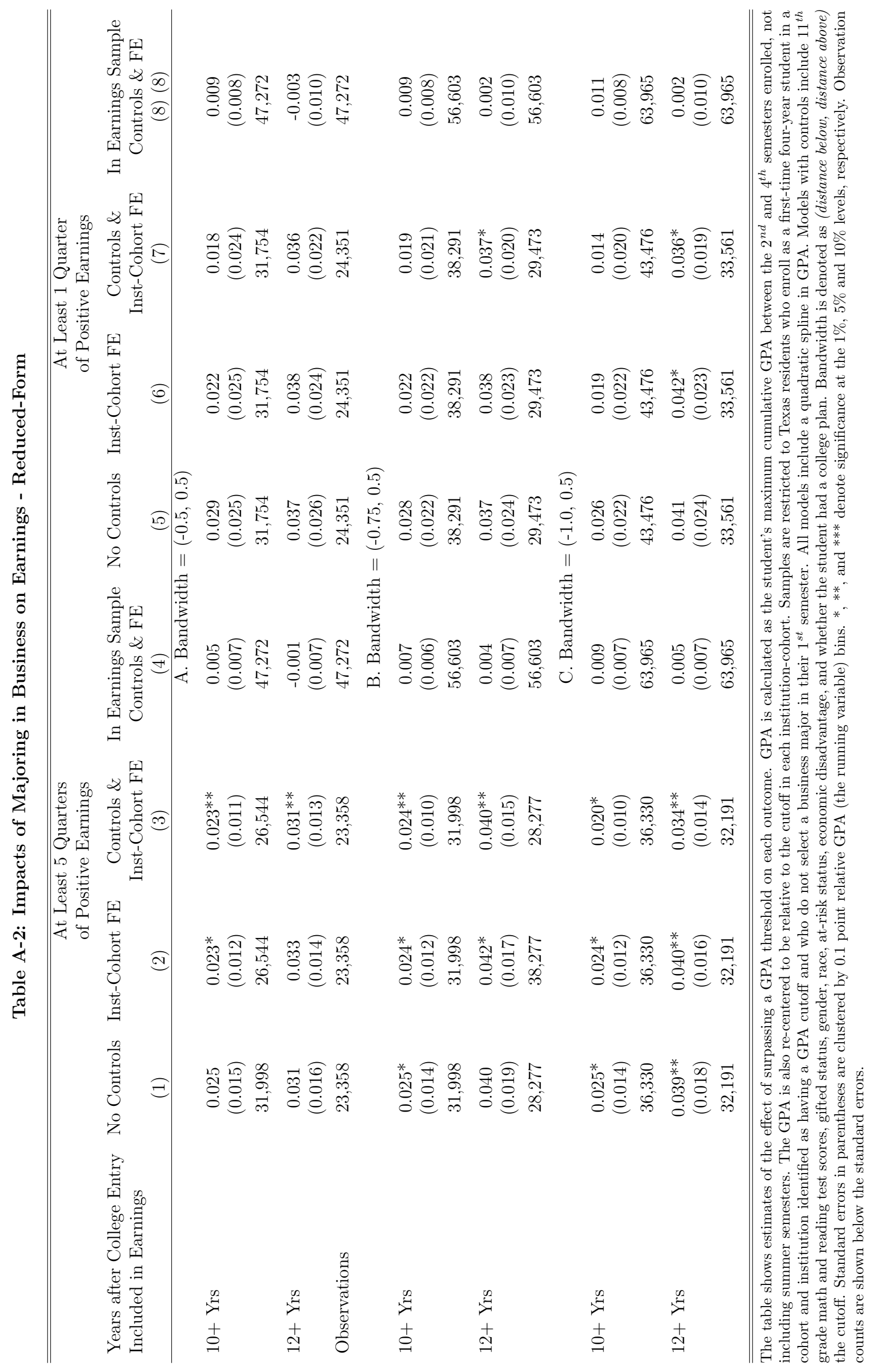




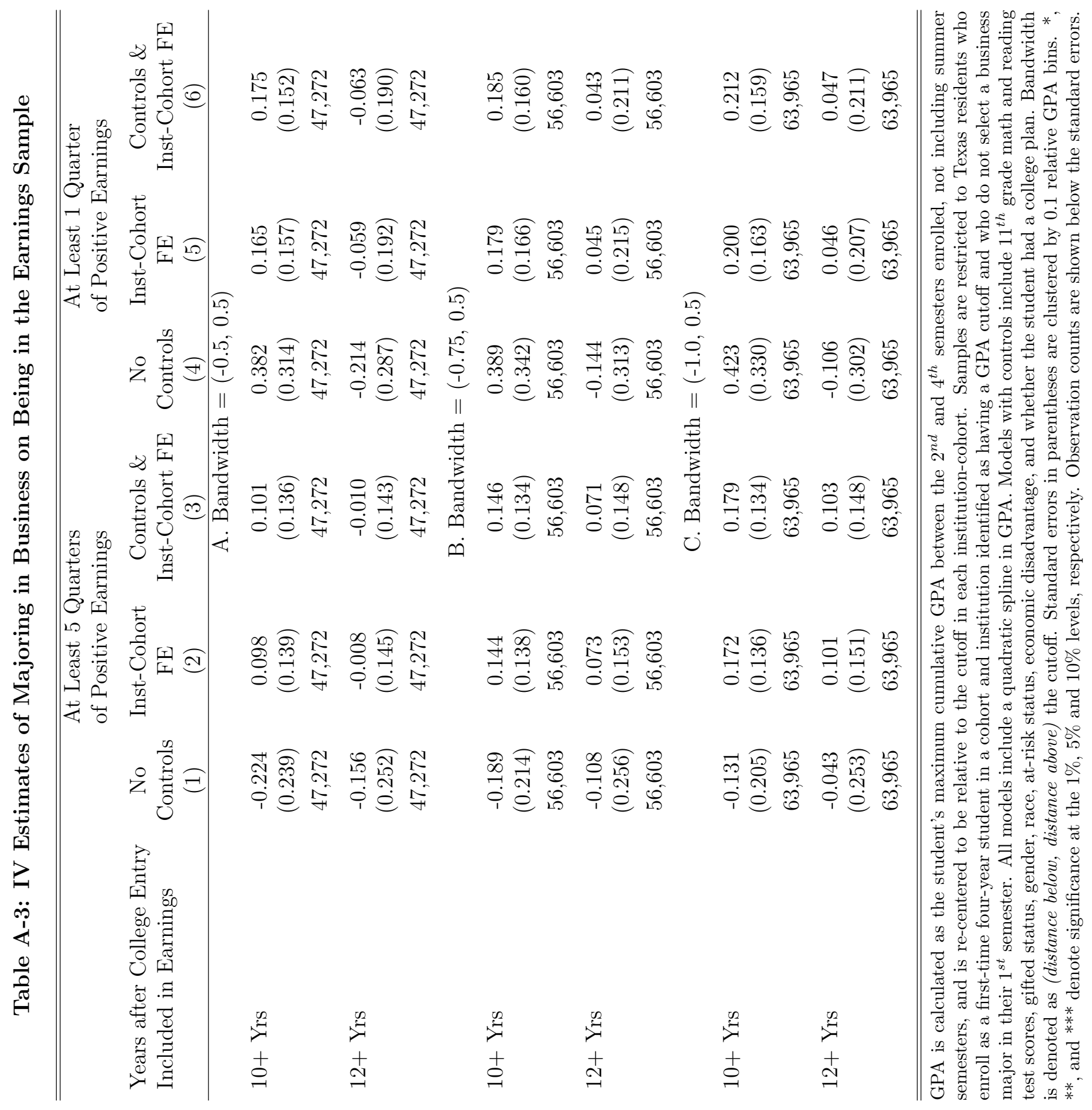




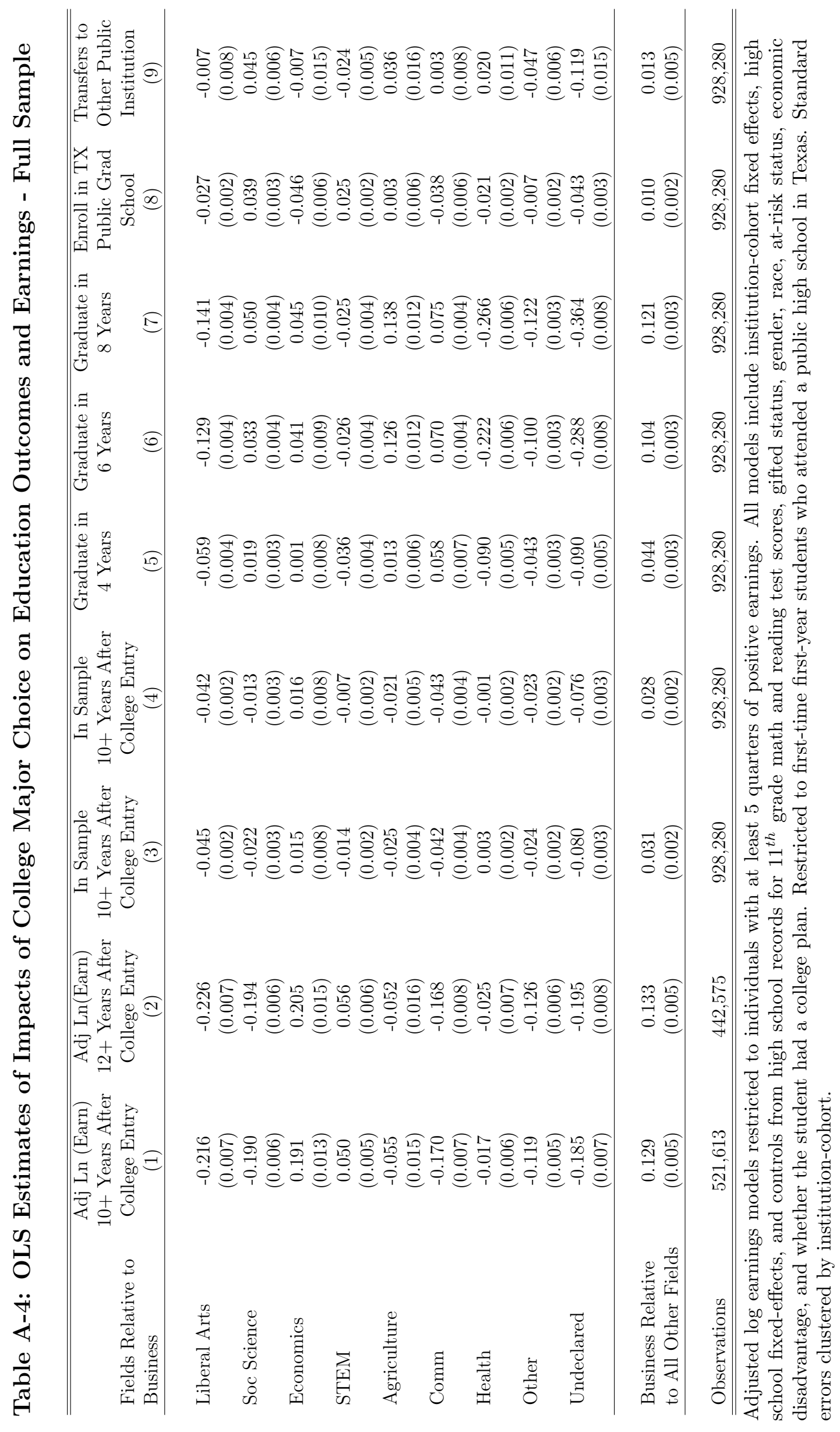




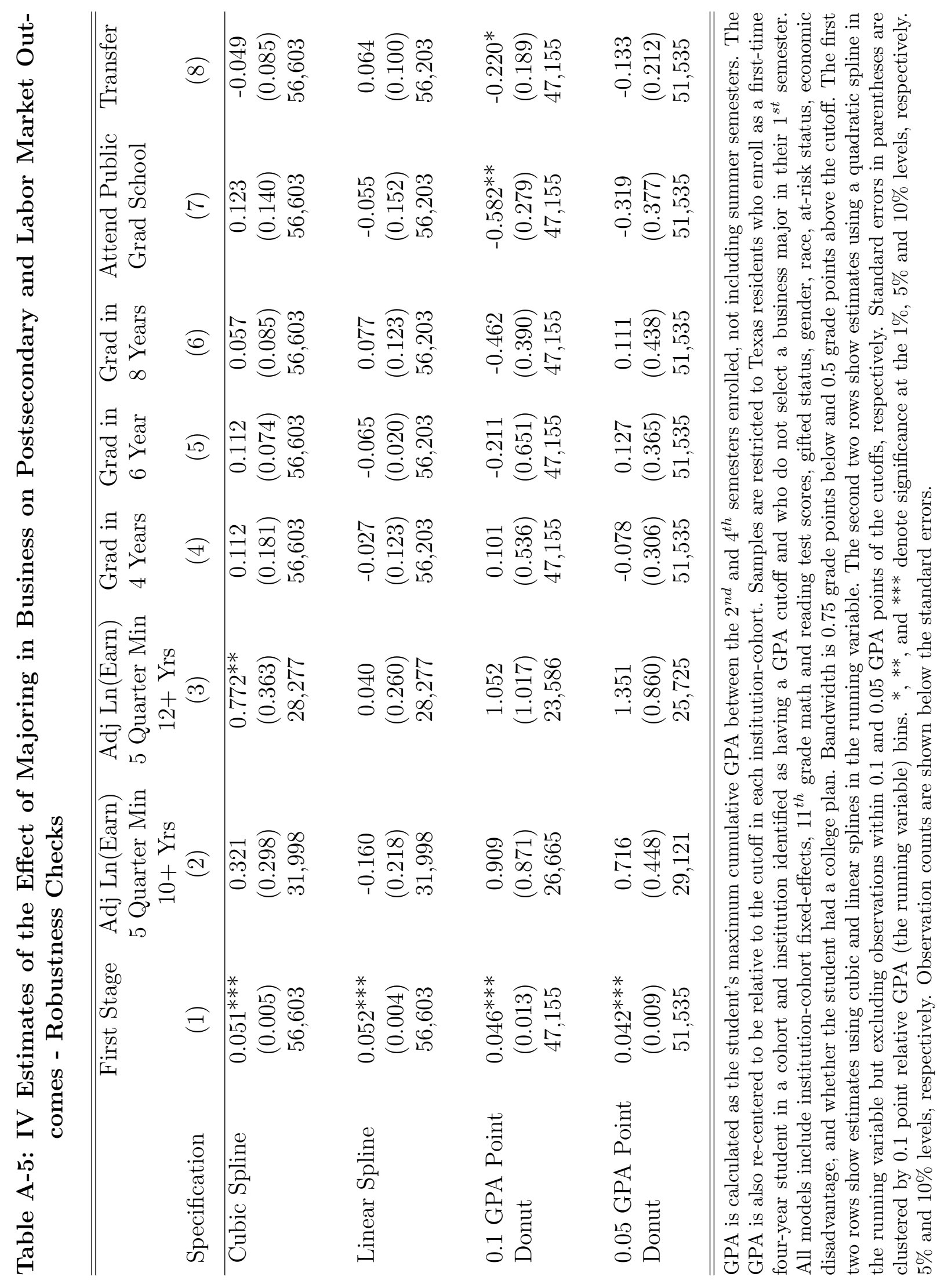

